\title{
Educación y formación para el trabajo: inclusión social, productiva
}

\section{y económica}

\section{Education and working skills: productive, economic and social inclusion}

\section{$\{\text { Martha Elena Pacheco Restrepo }\}^{*}$}

Doctora en Derecho y Ciencias Políticas, Universidad Santo Tomás, Bogotá. Exjefe del Programa Regional para las Américas del Centro Internacional de Formación de la orт y exdirectora del Centro Interamericano para el Desarrollo del Conocimiento en la Formación Profesional (orт/Cinterfor). Correo electrónico: marthapachecorestrepo@gmail.com / DOI: https://doi.org/Io.I860 I/25390406.nI.07 Recibido: I de junio de 2016

Aprobado: 2 I de noviembre de 2016 


\section{RESUMEN}

Colombia no es ajena al debate internacional sobre la calidad y pertinencia de la educación que debe permitir a las personas acceder a un trabajo decente y productivo, dependiente o independiente. No obstante los esfuerzos dirigidos a obtener tales propósitos, los resultados no son halagüeños; en efecto, el sistema educativo continúa centrado en disciplinas tradicionales, alejadas de los requerimientos del mercado de trabajo; los conocimientos y las competencias que adquieren las personas, en especial los jóvenes, no responden a las necesidades del sector productivo lo que afecta la inserción y la productividad laboral. El presente documento, basado en diferentes estudios sobre el particular, se refiere a: cantidad y calidad de la educación, la formación por competencias, la empresa como lugar de aprendizaje, con énfasis en las directrices de la Comisión Europea sobre la formación en el lugar de trabajo, el origen y desarrollo de la formación profesional en América Latina y las recomendaciones que para Colombia ha hecho el Consejo Privado de Competitividad

\section{PALABRAS CLAVE}

Calidad de la educación; competitividad; formación por competencias; mercado laboral; trabajo decente

\section{ABSTRACT}

Colombia is not absent to the international debate upon quality and relevance of the education, allowing people to have access to a decent and productive job as a self-employed or as an employee. However all efforts perusing such purposes and their results are not the best. In fact, the education system is basically centered upon traditional disciplines, far away from the market requirements. Knowledge and competences obtained specially by young people are not the answer to the needs of the productive sector which affects the insertion and labor productivity. This document based upon different studies on the subject refers to: quantity and quality of education, education for competences, enterprises as a mean for learning following the guidelines of the European Commission upon training in the working place, origin and development of professional skills in Latin America and the recommendations for Colombia as per the Competitiveness Private Council.

\section{KEYWORDS}

Competitiveness; decent job; education quality; job market; training for competences 


\section{El derecho al trabajo, la educación y la fORmación para el trabajo}

La Declaración Universal de Derechos Humanos de las Naciones Unidas prevé que toda persona tiene derecho al trabajo ${ }^{\mathrm{I}}$. Correlativo con tal derecho, una obligación fundamental de toda sociedad es la de garantizar oportunidades para acceder a un trabajo decente y productivo, para lo cual es esencial contar con políticas dirigidas a promover el acceso a educación y formación profesional pertinentes y de calidad. Tales políticas, articuladas con las económicas, de empleo y otras de naturaleza similar, contribuyen a la inclusión social de los habitantes de un país.

\section{LA EDUCACIÓN BÁSICA: CANTIDAD Y CALIDAD}

Los países de América Latina han hecho un gran esfuerzo para ampliar la cobertura de la educación. En efecto, el 96\% de los niños en la edad correspondiente al nivel primaria está matriculado en la escuela, mientras que en secundaria está el $73 \%$ de los jóvenes, cuya edad corresponde a tal nivel; cifra muy superior al $65 \%$ registrado en la década del noventa, pero significativamente inferior al 9i \% de las economías de los países que conforman la Organización para la Cooperación y el Desarrollo Económico (ocDED)².

Sin embargo, la calidad de la educación es deficiente y su orientación, de sesgo academicista, poco aporta a la formación de recursos humanos capacitados para responder a las necesidades de la actividad productiva. Los gobiernos de América Latina invierten en educación porcentajes muy similares a países de la ocded, como Alemania, Francia o Suecia, e incluso más que países como Bélgica o Suiza. No obstante, la región está en el tercio inferior de los 65 países que participan en las pruebas $\mathrm{PISA}^{3}$, en lectura, matemáticas y ciencias. El $48 \%$ de los estudiantes de la región tienen dificultades para comprender un texto y el $62 \%$ no puede realizar cálculos numéricos básicos.

En cuanto a la educación financiera, en las pruebas PIsa de 2014, los estudiantes de colegio de Colombia se situaron en el último lugar de los países evaluados. En esta prueba fueron analizados los conocimientos en asuntos como la gestión de cuentas y tarjetas bancarias, la planificación de finanzas, la comprensión de los riesgos, intereses o impuestos y de sus derechos y deberes como consumidores ${ }^{4}$.

I Declaración Universal de Derechos Humanos de las Naciones Unidas, I948, art. 23.

2 Cfr. Marina Bassi et al., Desconectados: Habilidades, educación y empleo en América Latina (Washington: BID, 2OI 2).

3 Programa Internacional de Evaluación de los Alumnos, que lleva a cabo ocDED.

4 Cfr. Portafolio, 27 de enero de 2015. 
Así las cosas, el joven colombiano promedio no tiene las capacidades mínimas para resolver problemas básicos de la vida real. Tal es la situación de aquellos que están dentro del sistema educativo de América Latina. Pero es más complicado aún el panorama de quienes abandonan sus estudios antes de finalizarlos. La tasa de culminación para el primer ciclo de educación secundaria (9 años) apenas supera el 50\% de los jóvenes de quince a diecinueve años. Respecto de la secundaria completa (I 2 años), la tasa es cercana al 40\% entre los jóvenes de 20 a 24 años. Esto quiere decir que solo uno de cada dos jóvenes termina el primer ciclo de secundaria y solo dos de cada cinco la completan antes de los 24 años. Como consecuencia, para los jóvenes latinoamericanos la transición de la escuela al trabajo es muy compleja, tanto por las falencias en conocimientos básicos, como por la brecha entre las habilidades que se adquieren en la escuela y las que demanda el sector productivo. Por ser la escuela secundaria el último contacto con el sistema educativo es preciso retener a los jóvenes hasta culminar sus estudios, así como brindarles las competencias que exigen el mundo laboral y la sociedad, para lo cual es necesario ir más allá de la memorización y la aplicación mecánica de procedimientos, a las que se reducen gran parte de las sesiones pedagógicas 5 .

Asimismo, es preciso atraer a mejores candidatos a la profesión docente y promover entre ellos buena formación y acompañamiento, pues:

... en Colombia, quienes ingresan a la carrera docente son, en términos generales, los bachilleres con más bajos resultados en la pruebas Saber. No solo no se está atrayendo al mejor capital humano a la carrera docente, sino que únicamente 9,5\% de los programas de ciencia de la educación cuenta con acreditación de alta calidad y los graduados universitarios con peor desempeño en las pruebas Saber Pro son precisamente los de carreras afines a la educación... 6 . Para completar el panorama, no existen incentivos al mejoramiento permanente de los docentes pertenecientes al antiguo estatuto (que representan la mayoría), los cuales no fueron evaluados para su ingreso, ni han sido evaluados para su permanencia o ascenso. Adicionalmente, falta mucho por hacer para mejorar la valoración social de la docencia e incrementar el estatus [socioeconómico] de éstos. Finalmente, no existe un plan para fomentar la acreditación de alta calidad de los programas de licenciaturas...7. Amerika (blog), 16 de enero de 2 ro4, https://goo.gl/6rqzcd.

6 Cfr. Felipe Barrera Osorio, Darío Maldonado y Catherine Rodríguez, "Calidad de la educación básica media en Colombia: diagnóstico y propuestas" (Documento, Serie de documentos cede, núm. 4I, noviembre de 20I2), I4, https://goo.gl/uY47MJ.

7 Cfr. Consejo Privado de Competitividad, "Informe Nacional de Competitividad 20r4-2015" (Informe, Bogotá, I 8 de octubre de 20I4), https://goo.gl/zBLjN 7 . 


\section{El desarRollo de LOS ReCURSOS humanos: LA FORMACIÓN TÉCNICO PROFESIONAL}

El mundo del trabajo se enfrenta a grandes desafíos relacionados con fenómenos sociales y tecnológicos, cada vez más dinámicos. Esto hace que el desarrollo de los recursos humanos sea un aspecto central de articulación para facilitar el acceso a mejores empleos e ingresos, así como para aumentar la productividad y la competitividad.

Existe un consenso cada vez mayor sobre la importancia y valoración de la formación técnico profesional (FTP), integrada por las dimensiones laboral, tecnológica, educativa y social. Su dimensión laboral se evidencia en que es objeto de interés, negociación y financiación por los interlocutores sociales, además de guardar un estrecho vínculo con todos los temas de las relaciones del trabajo (productividad, seguridad y salud, igualdad de oportunidades, salarios, etc.). La dimensión tecnológica se manifiesta cuando la formación abarca un amplio abanico de servicios especializados para los sectores económicos y las comunidades. La dimensión educativa se refleja a través de su relación con otros entes que trabajan desde la perspectiva de la educación, a lo largo de la vida; y la social, en la medida en que los programas de capacitación se enlazan con los orientados a las necesidades de las poblaciones vulnerables al desempleo, así como al desarrollo local, sectorial y empresarial.

Los países de América Latina y el Caribe han mostrado, en los últimos años, cifras importantes de crecimiento económico acompañadas de resultados positivos en materia de empleo; en efecto en 2012 se registró la tasa más baja de desempleo urbano desde los años noventa, siendo esta de 6,4\% de la población económicamente activa. No obstante, persisten desafíos que deben afrontarse. De hecho, el desempleo de los jóvenes es de $14,3 \%$, tres veces más que el de los adultos, y el desempleo de la mujer es $\mathrm{I}, 4$ veces el de los hombres.

Muchos jóvenes tropiezan con dificultades a la hora de encontrar un empleo, porque sus calificaciones educacionales no se ajustan a aquellas que exigen los empleadores. Por una parte, no hay suficientes puestos de trabajo altamente calificados a los que puedan aspirar los jóvenes titulados universitarios, aunque existe una gran demanda insatisfecha de técnicos de todos los niveles y de trabajadores manuales calificados; por otra, como ya se mencionó, la calidad de la educación y la formación no es acorde con los requerimientos del mercado laboral.

La ocDed y la Comisión Económica para América Latina y el Caribe (CEPAL) han expresado que si bien se han realizado importantes avances en términos de acceso y permanencia, persisten grandes brechas en materia educacional “... el cambio tecnológico y la paralela transformación del modelo productivo han estimulado la aparición de ocupaciones que demandan nuevas destrezas, mien- 
tras que actividades repetitivas que tradicionalmente realizaban trabajadores con educación media están siendo sustituidas gradualmente por tecnologías...”.

Este debate no es exclusivo para América Latina y el Caribe. En otras latitudes se aboga por una educación estrechamente vinculada al mundo del trabajo. Un estudio de la Universidad de Harvard ${ }^{9}$ indica que el sistema estadounidense de preparar a los jóvenes para llevar vidas productivas y prósperas como adultos está claramente debilitado, al no contar con las competencias que demanda el mercado y que una respuesta más adecuada la dan los community colleges, que ofrecen a jóvenes que han cursado uno o dos años de formación técnica acredita$\mathrm{da}$, la oportunidad para obtener un trabajo remunerado en mejores condiciones que otros que han completado cuatro años de universidad.

En contraste, la misma publicación se refiere a experiencias de países del norte de Europa que han logrado desarrollar habilidades ocupacionales adecuadas en los jóvenes, permitiéndoles una transición más fácil a la edad adulta. Estas lecciones confirman que programas de FTP pertinentes y de calidad ofrecen claras vías de inserción en la fuerza de trabajo, así como corroboran la hipótesis de que la mayoría de los jóvenes aprenden mejor en programas que combinan trabajo y aprendizaje, donde este último es contextual y aplicado.

Diversas investigaciones demuestran que:

... los estudiantes con educación universitaria presentan niveles más bajos comparados con los que alcanzan un nivel técnico-profesional, lo cual puede estar relacionado con el efecto que produce culminar el nivel de escolaridad alcanzado: quienes terminan un nivel educativo muestran mayores habilidades que quienes no lo hacen ... Esto, sumado a la alta deserción que existe en la formación universitaria, hace que el promedio de habilidades de quienes culminaron y no culminaron la universidad sea inferior al promedio que se registra en la educación técnica superior .... ${ }^{10}$.

Sin embargo, persisten prejuicios culturales para conceder a la FTP el realce social y económico que ostenta como motor de inclusión laboral. Muchos estudiantes, y sus padres, se plantean en algún momento continuar su preparación más allá de la enseñanza obligatoria y, con frecuencia, surgen las opciones de la FTP o de la universidad. A la hora de decidir, priman tales prejuicios, trayendo como con-

8 Cfr. OCDED, CEPAL, Perspectivas económicas de América Latina 2013: politicas de pymes para el cambio estructural (ocDED, CEPAL, 201 2), I47, doi http://dx.doi.org/ıo. I $787 /$ leo-20I 3 -es.

9 Cfr. Harvard, Graduate School of Education, "Pathways to Prosperity" (Documento oficial, febrero de 2O I I), https://goo.gl/iRoNHw. 
secuencia un superávit de titulados universitarios que no tienen las competencias para responder a las necesidades del mercado de trabajo ${ }^{11}$.

\section{EL DESARROLLO DE LOS RECURSOS HUMANOS POR COMPETENCIAS}

La Recomendación 195 (2004) sobre el desarrollo de los recursos humanos (RR. нн.) de la Organización Internacional del Trabajo (огт) ${ }^{\mathrm{I2}}$, refleja las condiciones económicas y sociales vigentes en el siglo xxi. En efecto, los avances tecnológicos, la creación de mercados mundiales de producción y servicios, la competencia internacional, las inversiones extranjeras directas, las nuevas prácticas de gestión y la organización de las empresas y del trabajo, aumentaron extraordinariamente la importancia de los recursos humanos para que las empresas, los trabajadores y los países aprovechen plenamente las oportunidades y enfrenten los desafíos.

El Centro Interamericano para el Desarrollo del Conocimiento en la Formación Profesional de la огт (oIT-Cinterfor), junto con la Red de instituciones que coordina, ha sido un importante impulsor de la formación basada en competencias, al considerar que la misma confiere una nueva forma de abordar temas críticos, tales como la definición de programas, la forma de ejecutar las acciones y el reconocimiento de saberes. La Red ha sido pionera en aprovechar las ventajas de enfocar la formación en los resultados, así como en el desarrollo de las competencias básicas, incluidas las de ciudadanía; las competencias técnicas y la flexibilidad facilitada por el diseño modular.

El desarrollo de competencias es un factor esencial tanto para alcanzar el objetivo del trabajo decente, como para aumentar la productividad y sostenibilidad de las empresas y mejorar las condiciones de trabajo y la empleabilidad de los trabajadores. Para asegurar el desarrollo efectivo de las competencias, se ha de adoptar un enfoque holístico. Ese enfoque abarca los aspectos siguientes:

- Métodos de aprendizaje continuos y uniformes que desde la educación preescolar y la escuela primaria preparen convenientemente a los jóvenes para la escuela secundaria, la educación superior y la capacitación profesional; proporcionen orientación profesional, información sobre el mercado de trabajo y asesoramiento a los jóvenes que se incorporan al mercado de trabajo; y, ofrezcan a los trabajadores y a los empresarios oportunidades de aprendizaje continuado con miras a mejorar sus competencias y adquirir nuevas calificaciones a lo largo de todas sus vidas. 
- Desarrollo de competencias básicas, incluida la alfabetización, el cálculo aritmético elemental, las aptitudes de comunicación, el trabajo en equipo, la resolución de problemas y la capacidad de aprendizaje, entre otras; así como la toma de conciencia acerca de los derechos de los trabajadores y el reconocimiento de la iniciativa empresarial como elementos fundamentales para el aprendizaje permanente y la capacidad de adaptación al cambio.

- Desarrollo de competencias de nivel superior, esto es, competencias profesionales, técnicas y en materia de recursos humanos.

- Portabilidad de las competencias basada, por una parte, en competencias básicas que permitan a los trabajadores aplicar sus conocimientos y experiencias en nuevos empleos o empresas y, por otra, en sistemas de codificación, normalización, evaluación y certificación de competencias que posibiliten a los interlocutores sociales reconocer fácilmente los niveles de calificación en diversos sectores laborales de los mercados de trabajo nacionales e internacionales.

- Empleabilidad (para el trabajo dependiente o el empleo por cuenta propia), que deriva de todos esos factores - un conjunto fundamental de competencias básicas, acceso a la educación, existencia de oportunidades de formación, motivación, capacidad y apoyo para aprovechar las oportunidades de aprendizaje continuado, y reconocimiento de las competencias adquiridas- y es esencial para que los trabajadores tengan un trabajo decente y gestionen el cambio y las empresas puedan adoptar nuevas tecnologías y captar nuevos mercados $^{\mathrm{I} 3}$.

La participación de los trabajadores y de los empleadores en la identificación y validación de competencias laborales se ha demostrado esencial para responder a las demandas de los sectores productivos, como lo corroboran numerosas experiencias, entre las cuales se pueden mencionar: los comités técnicos sectoriales del Servicio Nacional de Aprendizaje Industrial (senaI), de Brasil; la mesa de diálogo social y laboral promovida por el Servicio Nacional de Capacitación y Empleo (sence), de Chile; los organismos sectoriales del Instituto Salvadoreño de Formación Profesional de El Salvador (INSAFORP); los comités técnicos sectoriales del Servicio Nacional de Aprendizaje (sena), de Colombia; de las instancias tripartitas en la industria de la construcción de Argentina y de Perú, Unión Obrera de la Construcción de la República Argentina (Uocra) y Servicio

I3 Cfr. Organización Internacional del Trabajo (огт), Conclusiones sobre las calificaciones para la mejora de la productividad, el crecimiento del empleo y el desarrollo. Conferencia Internacional del Trabajo 2008, r. ${ }^{\text {a }}$ ed. (Ginebra, Suiza: Oficina Internacional del Trabajo, 2008), 2-3. 
Nacional de Capacitación para la Industria de la Construcción (sENcico), en su orden.

\section{Guía de Autoformación y Evaluación por Competencias (Gaec) en el SeCtor agrícola de Chile}

A comienzos de 2007 , en reuniones bilaterales de organizaciones de empresarios y de trabajadores del sector frutícola de Chile, se comenzaron a analizar aspectos de importancia común para los interlocutores sociales; y, en 2008, crearon varias instancias de diálogo social: la Mesa Frutícola (empleadores y trabajadores) y la Mesa Agrícola Laboral (tripartita). En ambas instancias, empresarios y trabajadores... del sector han reconocido la importancia de avanzar en la capacitación de los [trabajadores] de la fruta, en un contexto de diálogo [conducente] a la mejora continua de los procesos productivos, climas de trabajo y condiciones laborales... En este marco se elabora la Guía de Autoformación y Evaluación por Competencias (GAEC) para este sector clave de la economía chilena, en diferentes cultivos y procesos, entre los cuales: cosecha y empaque de manzana, uva, cereza, palta, kiwi. La GAEC orienta, facilita y evalúa aprendizajes efectivos en adultos, de manera continua, individual y colectiva, también entre las personas y [las] organizaciones, mejorando procesos, formas y maneras de trabajar desde el mismo saber de [los trabajadores]. Incluyen temáticas de género, autocuidado, trabajo en condiciones dignas, en el marco del diálogo social' ${ }^{\mathrm{T} 4}$.

\section{Certificación de competencias laborales para inCRementar LA COMPETITIVIDAD EN LA INDUSTRIa del PLÁstico de El SALVAdOR}

El InSAForp y la Asociación Salvadoreña de la Industria del Plástico (ASIPLASTIC) iniciaron en 2008 y concluyeron en 2013 , el programa arriba indicado, dirigido al fortalecimiento del desarrollo de los recursos humanos en la industria del plástico.

Los objetivos principales fueron:

- El reconocimiento de las competencias de los trabajadores, adquiridas en la práctica, en el trabajo o en acciones de formación técnica.

- El aprendizaje permanente en pro de la adaptación a los cambios, la innovación y diversificación productiva.

I4 Modificado de Eduardo Aranciba Muñoz y María Antonieta Palma Díaz, eds., "Mejorando la productividad y la calidad: packing de uva" (Guía de Autoformación y Evaluación por Competencias (GAEC), Ministerio de Agricultura, Gobierno de Chile, diciembre de 2009). 
- La promoción de la movilidad y empleabilidad de los trabajadores al interior de las empresas y en el sector.

- La identificación de necesidades de capacitación.

- La reducción de los costos en la selección, reclutamiento e inducción del personal.

Los resultados más destacados del programa: la normalización de los procesos con los correspondientes instrumentos didácticos, un libro de competencias transversales y cuatro de competencias específicas; la formación de formadores y evaluadores; el fortalecimiento de los trabajadores en competencias transversales y específicas. En total, se certificaron $45^{2}$ trabajadores y se formaron 33 evaluadores y 8 formadores por competencias laborales.

Adicionalmente, se identificaron cuatro nuevas carreras técnicas en la modalidad dual de formación (empresa-centro): operador de máquina de extrusión de película de polietileno; operador de máquina de moldeo por inyección; operador de máquina de moldeo por soplado y operador de máquina de impresión flexográfica ${ }^{15}$.

\section{LA EMPRESA COMO LUGAR DE APRENDIZAJE en EUROPA: la fORMACIÓN dUAL ${ }^{16}$}

La formación para el trabajo y especialmente la que tiene lugar en las empresas, han demostrado la eficacia de un sistema que conecta el trabajo con el aprendizaje a partir de la educación secundaria. Los países más avanzados del norte y centro de Europa confieren mayor énfasis a la formación vocacional, que los de América Latina y Estados Unidos, lo que permite a los jóvenes hacer el tránsito de la adolescencia a la mayoría de edad de manera productiva.

En Alemania, Austria, Dinamarca, Finlandia, Holanda y Suiza, entre el 40\% y el 70\% de los jóvenes que cursan la escuela media optan por un programa educativo que combina las aulas con el lugar de trabajo durante tres años, al culminar el cual obtienen un diploma o certificado, llamado "calificación" con un valor real en el mercado de trabajo ${ }^{17}$.

La educación secundaria superior o formación técnica vocacional, como es también llamada, varía según los países europeos y básicamente se pueden identificar dos modelos: en el primero, conocido como aprendizaje en alternan-

I 5 Cfr. "8. a edición del Seminario Especializado en Flexografía de la Región Centroamericana 'Flexo 2015 ", consultado en septiembre de 2016 , https://goo.gl/XnkTJR.

I6 La información de este apartado ha sido tomada y traducida del documento "Work-Based Learning in Europe, Practices and Policy Pointers" de la Comisión Europea. 
cia o sistema dual, los estudiantes permanecen tres o cuatro días en una empresa aprendiendo en sus instalaciones y reciben una remuneración, mientras que uno o dos días asisten a las aulas de clase para adquirir conocimientos académicos relacionados. Alemania tiene el más antiguo y más reconocido sistema de aprendizaje que permite adquirir las competencias necesarias en más de 350 ocupaciones. Suiza tiene, igualmente, un muy importante sistema de aprendizaje.

En el segundo grupo se encuentran los países que han optado por un modelo en el cual la formación es mayormente provista en instituciones de formación, no obstante lo cual incorporan el aprendizaje basado en el trabajo.

La formación en el lugar de trabajo (FLT, wBL por sus iniciales en inglés: Work-Based Learning) asegura a los jóvenes oportunidades reales para incorporarse en el mercado laboral, mejora la empleabilidad de las personas e incrementa la competitividad de los países, tal como lo demuestran las experiencias de países como Alemania, Austria, Dinamarca y Suiza.

La falta de experiencia laboral y las habilidades y competencias correlativas son los factores que determinan la brecha de habilidades que existe en la Unión Europea: mientras que 5,6 millones de jóvenes sufren las consecuencias del desempleo, $36 \%$ de los empleadores reporta que no encuentran los trabajadores con las habilidades que requieren.

En parte, la solución se puede encontrar en la formación vocacional de calidad, con la activa participación de los empleadores y un amplio aprendizaje en las empresas que faciliten a los jóvenes insertarse en el mercado de trabajo, dotándolos de los conocimientos, habilidades y competencias pertinentes.

A continuación se describen las directrices y prácticas destacadas por la Comisión Europea $(\mathrm{CE})^{18}$, la cual reconoce el valor de la formación dual y promueve ampliamente la FLT, definiendo políticas y líneas de acción ilustradas con las mejores prácticas. Los beneficios que ha subrayado:

- Para los estudiantes/aprendices:

- Desarrollo de habilidades manuales, técnicas y adquisición de experiencia laboral.

- Fortalecimiento de las habilidades y competencias necesarias para desempeñarse en el trabajo, incluyendo las transversales, tales como: comunicación, trabajo en equipo y solución de problemas.

- Mayor información sobre opciones de carrera.

- Progreso en las competencias de gestión.

- Aumento de la confianza y la motivación.

- $\quad$ El tener una experiencia laboral facilita el ingreso al mercado de trabajo.

I8 Cfr. Comisión Europea, "Work-Based Learning in Europe, Practices and Policy Pointers" (Documento oficial, junio 20I3), https://goo.gl/hnoEGp. 
- Para los empleadores:

- Incremento de la oferta de trabajadores calificados.

- Disminución de la brecha de habilidades, gracias a la formación a medida.

- $\quad$ Efecto positivo en el reclutamiento y retención de los trabajadores.

- Mejoramiento de la productividad y el rendimiento empresarial.

- Aporte al desarrollo de los recursos humanos.

- Para los proveedores de formación:

- Más calidad de los programas y de los resultados.

- Realce de la pertinencia y del interés en la formación.

- $\quad$ Efectos favorables en el desarrollo de las competencias de los formadores.

- Mayor cooperación entre las instituciones y los empresarios.

- Para la sociedad:

- Recursos humanos que respondan mejor a las necesidades del sector productivo.

- Contribución favorable para el empleo de los jóvenes.

- Distribución de costos de la formación entre el Estado y los empleadores.

- Acuerdos de gobernanza sobre la formación para el trabajo.

- Aportes a la innovación y creatividad.

- Potencial para fortalecer la inclusión social y la igualdad de oportunidades.

Los anteriores beneficios se consiguen en la medida en que se cumplan condiciones esenciales de gobernanza, calidad y asociaciones. Integrar la capacitación en el trabajo dentro de la educación y los sistemas de formación y, especialmente en el aprendizaje, en un sentido amplio, es la primera condición de éxito.

Para que las sendas de la alternancia sean atractivas para los estudiantes y los empleadores tienen que ser permeables, es decir estructuradas de manera que permitan a las personas poder acceder a formación adicional, continua y avanzar en su educación superior. Las calificaciones tienen que estar claramente vinculadas y arraigadas en el conjunto del proceso formativo.

En cada programa de capacitación dual es importante que los aspectos de la FLT estén claramente articulados con la escuela, complementándose mutuamente; es un factor clave el reconocimiento de lo aprendido en la empresa, asegurando la coherencia en este estadio, así como es necesario que el aprendizaje académico sea tenido en cuenta por las empresas. 


\section{El MARCO REGULAdOR PARA El APRENDIZAJE EN EL LUGAR DE TRABAJO}

Quienes están matriculados en alternancia/aprendizaje se encuentran entre los estudios y el empleo, están aprendiendo y al mismo tiempo toman parte en los procesos productivos de una empresa, la cual se beneficia de su trabajo. Por lo tanto, se requiere de un marco específico que defina las responsabilidades, derechos y obligaciones de cada parte, el que debe precisar el estatus del estudiante, los acuerdos de remuneración y otros beneficios (si se aplican), junto con las obligaciones del empleador, del estudiante y del proveedor de formación.

Entre otros aspectos, se debe asegurar que los empleadores no utilicen a los aprendices para reemplazar trabajadores regulares y que las cargas administrativas impuestas a los empresarios no sean gravosas. Asimismo, se requiere que exista un marco de más alto nivel que incluya responsabilidades para el desarrollo de estándares de calificaciones, currículos, planes de aprendizaje y aseguramiento de la calidad a través de revisiones y evaluaciones.

\section{Marco Regulador Claro}

Los modelos de aprendizaje de Alemania, Austria y Suiza están bastante institucionalizados con requisitos para contribuir al conjunto de la calidad de los programas. En Alemania, por ejemplo, la Ley de Formación Vocacional de 1969 define los parámetros dentro de los cuales las empresas y las Cámaras de Comercio pueden legalmente realizar contratos de aprendizaje; determina la duración de la formación, los exámenes que deben llevarse a cabo por las Cámaras para comprobar el aprendizaje y obliga a los empleadores a permitir a los aprendices a tomar estas pruebas. También confiere a los aprendices el derecho de emprender acciones legales si el empleador no cumple con sus obligaciones. Las Cámaras regularmente controlan a las empresas y tienen la facultad para retirar los permisos de aprendizaje si las firmas no satisfacen los estándares de calidad ${ }^{19}$.

\section{LA ACTIVA Y CERCANA PARTICIPACIÓN DE LOS INTERLOCUTORES SOCIALES}

La participación de los interlocutores sociales es necesaria para asegurar que la FLT responda a las competencias requeridas, tanto presentes como futuras. La formación y sus estándares requieren ser revisados y actualizados regularmente y son los actores sociales los que están mejor posicionados a propósito; ellos tienen experiencia directa para identificar los más apropiados para tener éxito en la 
búsqueda de la empleabilidad y competitividad, y son de particular utilidad para llegar a arreglos con los proveedores de formación en tal sentido.

\section{INCENTIVOS PARA LOS EMPLEADORES}

La FLT exige que las compañías estén comprometidas, ofrezcan puestos para el aprendizaje y colaboren con las escuelas; si bien para las empresas implica un costo, también les genera beneficios e incluso ganancias financieras.

Las regulaciones deben ser claras respecto de los incentivos en los programas de alternancia, los cuales pueden ser financieros, tales como la reducción de impuestos, subsidios u otros, así como también no financieros, como servicios de apoyo y en los trámites relativos a la vinculación de aprendices. En efecto, deben tenerse en cuenta varios aspectos: la duración del aprendizaje y el tiempo que efectivamente se realice en la empresa, las reglas sobre salarios, los beneficios y contribuciones sociales, las necesidades de instalaciones, equipos, materiales y la posibilidad de contratar al estudiante en tareas productivas.

En Francia, los empleadores tienen exenciones sobre las contribuciones fiscales y reciben un bono por contratar aprendices; en Holanda, son elegibles para reducciones de impuestos y contribuciones a la seguridad social; en Alemania, con el propósito de aumentar el número de puestos de formación, las empresas tienen apoyo para implementar estos programas cuando no han tenido experiencia previa; en Dinamarca, se ha creado una iniciativa para crear 5000 nuevas pasantías y se ha triplicado el subsidio que se paga a los empleadores por vincular aprendices.

\section{LA FLT EN LAS PEQUEÑAS Y MEDIANAS EMPRESAS}

Las pequeñas y medianas empresas (pyme), enfrentan desafíos particulares para abordar este tipo de formación, considerando el limitado número de trabajadores, de recursos y la falta de familiaridad con las regulaciones y asuntos administrativos.

Para enfrentar estas dificultades, la colaboración de entes intermediarios, como las cámaras empresariales, pueden ser de gran utilidad informándolas sobre diversos temas como pueden ser las cargas administrativas y beneficios fiscales.

\section{Redes DE "entes intermediarios" a tRavés dE LAS fronteras ${ }^{20}$}

El proyecto EuroAprendizaje (EuroApprenticeship Project)21 , es una red de más de $35^{\circ}$ organizaciones, entes intermediarios e instituciones proveedoras de for-

\footnotetext{
20 Cfr. Ibíd., i4.

2 I Carsten Becker "Accompanying Research for the Special Programme of the Federal Government for 
mación profesional, que tienen competencia regional o sectorial en temas de aprendizaje. Estas organizaciones utilizan sus propias redes de empresas e instituciones de formación para promover la movilidad laboral transnacional de los aprendices.

Se han desarrollado herramientas para apoyar la promoción, organización, validación y la calidad de los proyectos de movilidad, tales como: bases de datos de socios; un observatorio de los sistemas de aprendizaje y movilidad laboral; un barómetro para medir la opinión y conocimiento de los empleadores sobre la movilidad, y una etiqueta que reconoce a las compañías comprometidas con la movilidad de los aprendices. Este apoyo es clave para conseguir la participación de las pyme en la formación de aprendices a través de las fronteras.

\section{Atención de LAS POBlaciones en RieSGO}

Los jóvenes que abandonan tempranamente la escuela, o que están en riesgo de hacerlo, los jóvenes con bajas calificaciones, los inmigrantes o aquellos que pertenecen a poblaciones vulnerables necesitan apoyo adicional para aplicar al aprendizaje; ellos se benefician de "medidas de transición", por lo general experiencias prácticas, a manera de un puente para acceder a la educación vocacional antes de incorporarse tiempo completo en estos programas. Especialmente, se trata de ayuda para desarrollar o mejorar las competencias básicas para tener éxito en las siguientes etapas de formación o el empleo.

\section{El programa EQJ de Alemania 22}

Este programa tiene el objetivo de apoyar a los jóvenes para avanzar en su educación y formación después de que han terminado la educación obligatoria y que no cuentan con un contrato de aprendizaje en el sistema de educación vocacional. Más de 40 mil estudiantes participan anualmente; es fundamentalmente una inducción en las empresas que dura entre seis y doce meses, para tener experiencias significativas sobre el mundo del trabajo.

El aprendizaje hace hincapié en las habilidades básicas de las ocupaciones definidas en el sistema dual. Los estudiantes tienen la oportunidad de participar en módulos, tanto de calificaciones generales como específicas; los resultados son reconocidos por la empresa donde se han formado y por la cámara empresarial respectiva, para avanzar en los subsiguientes programas de aprendizaje. En febrero de 2012 el Gobierno Alemán declaró que cerca del 70\% de los par-

the Introductory Qualification of Adolescents. EQJ Programme" (Reporte final, The Federal Ministry for Labour and Social Affairs, Berlín, 2008) 
ticipantes en este programa consiguieron ubicarse en el sistema dual luego de completar su formación inicial.

\section{DefinIR ESTÁNDARES DE AMPLIA COBERTURA DE CONOCIMIENTOS, HABILIDADES Y COMPETENCIAS}

Un aspecto central de la calidad de la FLT son los perfiles relativos a los conocimientos, las habilidades y las competencias que los estudiantes desarrollan. La buena calidad del aprendizaje está relacionada con una amplia gama de competencias que, asociadas con lo aprendido en la escuela, tengan como resultado un perfil profesional completo y que permita a los estudiantes progresar en un campo profesional. Tal comprensión es necesaria para que las personas sean capaces de adaptarse a los cambios relacionados con nuevas tecnologías, procesos y tareas que surgen mientras que otras desaparecen.

La activa participación de los interlocutores sociales en la definición de los estándares es un factor decisivo para la calidad y el buen desarrollo de los sistemas duales o en alternancia. Los estándares de competencias deben ser tan amplios que abarquen una profesión de manera completa y dar a los aprendices las bases para, no solo hacer la transición al mercado de trabajo, sino también para futuras evoluciones, contando con competencias básicas bien fundadas.

\section{OfRECER DIVERSAS OPORTUNIDADES PARA LA FORMACIÓN EN EL LUGAR DE TRABAJO}

Toda vez que los aprendices permanecen largos períodos de tiempo en las empresas, es crucial que se les ofrezca una amplia diversidad de oportunidades de aprendizaje; la formación que es demasiado específica limita las oportunidades de movilidad y de avance. Los estudiantes necesitan ser expuestos a diversas situaciones y tareas por lo que los currículos deben definir una amplia gama de conocimientos, habilidades y competencias, incluidas las competencias clave. Las empresas, en especial las pequeñas, pueden cooperar estableciendo alianzas de formación para que los aprendices se familiaricen con diferentes tecnologías y procesos.

\section{LA DEFINICIÓN CLARA DE LOS RESULtAdOS Y OBJETIVOS DE LA FLT}

Todos los períodos de aprendizaje, aún los de corta duración, deben tener un claro propósito pedagógico, para lo cual es necesaria la definición de resultados y objetivos que tanto el aprendiz como el empleador deben conocer. Es fundamental una articulación clara entre los períodos de aprendizaje en el lugar de trabajo y los que se llevan a cabo en la escuela, lo que hace que, igualmente, el 
estudiante y el empleador identifiquen el conocimiento relevante para las habilidades y competencias que se espera sean aprendidas. Esto exige un claro entendimiento de las evaluaciones que se realicen y de los períodos que se analizarán.

\section{Preparar y apoyar a los estudiantes para la Flt}

Los estudiantes necesitan preparación y apoyo en su busca de empresas que los acojan para realizar su aprendizaje. Debido a presiones económicas, los empleadores prefieren estudiantes que hayan desarrollado ciertas competencias y actitudes para incorporarlos, lo que puede resultar discriminatorio. El aprendizaje debe ser accesible para todos, sin importar el género, raza, condiciones de discapacidad o dificultades para aprender, para lo cual es importante apoyar a los estudiantes en la forma de acercarse a las empresas, cómo encontrar la más apropiada, prepararse para entrevistas y normas de comportamiento en lugar de trabajo, entrenamiento y seguimiento. Tales servicios de apoyo pueden ser provistos por diferentes entidades, desde las escuelas, los servicios públicos de empleo, las instituciones de formación.

\section{Estrategias exitosas en Dinamarca ${ }^{23}$}

El instituto tecnológico Aalborg Technical College dispone de un servicio que asegura una mejor respuesta entre demanda y oferta de cupos para aprendizaje, a través de consejeros que tienen experiencia en sectores definidos, de manera que "pueden hablar el lenguaje de la industria".

A su vez, estos consejeros se han formado como tales. Igualmente, se ha elaborado un manual para asegurar que la escuela pueda ofrecer un buen servicio especialmente a las microempresas que tendrán por primera vez un aprendiz, para asegurar que tanto el estudiante como el empresario cuenten con información exacta y actualizada. Un elemento esencial es una base de datos digital que permite conocer las empresas que tienen aprobados puestos para aprendices, la renovación de los contratos y si tienen o no estudiantes.

En 20Io, cuando la crisis comenzó, las plazas para sus estudiantes crecieron en $28 \%$. De acuerdo con las empresas y los estudiantes, un factor de éxito fue el de utilizar datos para garantizar la adecuada correspondencia ente oferta y demanda, así como la cercanía de los consultores con las empresas y la confianza que ello ha generado. 


\section{ASOCIACIONES ESCUELA-EMPRESA}

En todos los modelos de FLT, las instituciones de formación profesional necesitan actuar en redes con los empresarios locales para ubicar las empresas apropiadas, de lo contrario los estudiantes corren el riesgo de no encontrar el lugar idóneo que les ofrezca el desarrollo de competencias apropiadas. Las escuelas que tienen buenos vínculos con los empresarios locales y establecen redes entre ellos consiguen ubicar adecuadamente a los estudiantes.

\section{La FLt en América Latina y el Caribe}

En la región los modelos de alternancia más difundidos son los de Alemania y Suiza, gracias a la influencia que su cooperación internacional ha tenido desde mediados del siglo xx. Los países de América Latina y el Caribe disponen de sistemas de formación profesional con elementos duales como el contrato de aprendizaje, ampliamente difundido y regulado de variadas formas, adaptado a través de los años, conservando el objetivo de brindar oportunidades de capacitación teórico-práctica a los jóvenes, para acercarlos al mundo del trabajo.

\section{ORigen Y CONSOLIDACIÓN DE LA FORMACIÓN PARA EL TRABAJO en América Latina y el Caribe}

La historia de la formación profesional institucionalizada comienza a partir de la creación del Servicio Nacional de Aprendizaje Industrial (senaI) en i942 y del Servicio Nacional de Aprendizaje Comercial (senac) en I946, en Brasil; las dos estrechamente ligadas a las confederaciones empresariales de la industria y del comercio. Estas instituciones pioneras han sido referentes obligados para el establecimiento de entidades similares en toda la región, aunque con variaciones importantes en cuanto a estructura, organización y cobertura. Es por tanto obligatorio referirse a lo que dichas entidades prevén y ejecutan en materia de FLT.

\section{Servicio Nacional de Aprendizaje Industrial (SENAI), Brasil}

Más allá de que la formación profesional es su actividad prioritaria y en cumplimiento de su misión, el seNaI lleva a cabo actividades tecnológicas, tales como laboratorios, investigación aplicada y desarrollo de productos, asesoría técnica e información tecnológica para las empresas.

Como corolario de la convergencia de políticas de inserción de los jóvenes en el mercado de trabajo, el aprendizaje es el fruto de iniciativas de vieja data en 
pro de la calificación de los jóvenes y el inicio de la trayectoria de formación de las personas.

El aprendizaje industrial ${ }^{24}$ es un proceso de formación profesional que busca proporcionar al aprendiz las competencias fundamentales para su inserción en el mercado de trabajo como un trabajador calificado, para actuar preferentemente en actividades industriales en diversos sectores de la economía.

\section{EL APRENDIZAJE INDUSTRIAL EN ALTERNANCIA Y EN LA EMPRESA}

Corresponde a un proceso educacional predefinido por el senAI; las actividades que se llevan a cabo en las instalaciones de la empresa se realizan de acuerdo con un plan establecido el que define criterios de control, insumos y otras condiciones relevantes. El aprendizaje que se realiza en la empresa obedece a cuatro circunstancias:

- Cuando para las ocupaciones no existan cursos de aprendizaje en el senar.

- Cuando el senar no disponga de vacantes.

- Cuando el senar no tenga cursos de aprendizaje en la localidad donde está ubicada la empresa.

- Cuando el senar y la empresa estén interesados en la realización de una asociación.

Si el plan de enseñanza comprende actividades en centros de la institución y en la empresa, se denomina formación dual; si se realiza únicamente en la empresa se denomina flt. En los dos casos el senai tiene la responsabilidad del programa de aprendizaje: provee los modelos de materiales didácticos; supervisa la realización de las actividades formativas en la empresa; indica los instrumentos de control y evaluación del rendimiento escolar y expide los certificados correspondientes a los aprendices. La selección de los candidatos está a cargo de la empresa, la cual se compromete a contratar la totalidad de los alumnos como aprendices al inicio del curso.

La formación que se realiza en la empresa implica un firme compromiso del empleador en especial en cuanto a las condiciones de seguridad y salud en el trabajo. Es imprescindible que la empresa designe un profesional para coordinar las actividades de los aprendices en el lugar de trabajo; el SENAI puede verificar las condiciones de tal coordinador y tomar medidas para este sea un "tutor de práctica profesional de aprendices en las empresas". Esta condición implica, inclusive, la determinación de las actividades a llevar a cabo en la empresa acordes con el plan de formación y de la capacidad de la empresa para ofrecer un amde São Paulo, Conselho Regional, $3^{\mathrm{a}}$ Edição, 20 I 5). https://goo.gl/5t8X I4. 
biente apropiado en términos de experiencia para la práctica profesional. Todas las actividades en la empresa deben tener un fin educativo.

Adicionalmente, el programa debe ser estructurado a partir de un perfil profesional preciso que responda a las demandas del mercado de trabajo en general, y no solo al puesto de trabajo en la empresa, de acuerdo con lo establecido por el sistema SENAI, por lo que es fundamental la estrecha colaboración entre el SENAI y la empresa.

\section{Proyecto "Mı Nuevo Mundo"25}

Es un programa de inclusión social realizado conjuntamente por el sENaI/São Paulo, el Servicio Social de la Industria (sEsI), la Superintendencia Regional de Trabajo y Empleo de São Paulo y las empresas, a través del cual se establece un vínculo entre el sector productivo y las personas con discapacidad para su incorporación en el mercado de trabajo.

Las personas con discapacidad son contratadas como aprendices y tienen acceso a un programa especial de capacitación profesional de SENAI en el cual, además, se trabajan aspectos como la autoestima y habilidades físicas a través del deporte. Durante tres años los aprendices desarrollan actividades que comprenden: deporte y calidad de vida, identificación de vocación profesional, inclusión digital, aumento de la escolaridad, ciudadanía, cultura y calificación laboral. El programa da prioridad a las condiciones individuales de cada participante quien es certificado de acuerdo con las competencias alcanzadas para valorizar sus logros y motivarlo a ir cada vez más adelante.

Los participantes son contratados como aprendices con una remuneración. Se acentúa en este proyecto el que, junto con el deporte y el aprendizaje, las personas con discapacidad fortalecen valores, el establecimiento y cumplimiento de metas, desarrollo social y de convivencia. Las empresas que se vinculan a este proyecto deben tener por lo menos roo trabajadores; su intervención les permite, a la vez que cumplir con la cuota de aprendices con discapacidad y preparar las condiciones internas del centro de trabajo, contribuir al desarrollo de los recursos humanos, por medio de capacitación reconocida y de alta calidad.

\section{Servicio Nacional de Aprendizaje Comercial (SENAC)}

El Programa de Aprendizaje ${ }^{26}$ llevado a cabo por las administraciones regionales del sENAC privilegia el desarrollo de las competencias básicas necesarias para el

25 Cfr. "Meu novo mundo. O projeto", FIESP, CIESP, consultado en septiembre de 20I6, https://goo.gl/ mUkvgX.

26 Cfr. "Aprendizagem Profissional Comercial", sEnAC, consultado en septiembre de 20I6, https:// 
ingreso de los jóvenes en el mercado de trabajo. En el ámbito de ese programa, los empleadores, además de cumplir con su obligación de contratar aprendices, desempeñan un papel activo haciendo parte del proceso de formación.

La organización curricular de los cursos se estructura sobre las competencias profesionales específicas de una ocupación, asociadas a un conjunto de competencias generales, que responden a la configuración de perfiles ocupacionales más complejos, teniendo en cuenta las exigencias para la inserción y permanencia de las personas en el mundo del trabajo.

Integra también el currículo, de forma inseparable del aprendizaje teórico, la práctica profesional en la empresa, la cual tiene como objetivo proporcionar al aprendiz la vivencia de las situaciones de trabajo relativas a la ocupación para la cual fue contratado. El desarrollo del currículo requiere el equilibrio entre teoría y práctica, mediante la definición de atribuciones que se establecen entre el seNAC y la empresa, lo que implica, entre otros asuntos, la determinación de cargas horarias y las responsabilidades de cada una de las partes que participan en las diversas etapas del programa de aprendizaje.

En el aprendizaje, la empresa actúa como asociada del SENAC y está obligada a designar uno o más empleados del establecimiento para acompañar al aprendiz en cada etapa de su proceso de estudio. El sENAC también hace el seguimiento, mediante reuniones de los responsables del acompañamiento de los aprendices y la evaluación que permite verificar el aprendizaje. La empresa está obligada a pagar al aprendiz una remuneración no inferior al salario mínimo legal por hora; las vacaciones del aprendiz deben coincidir con las vacaciones escolares; el aprendiz no puede hacer horas extras y, si es menor de i 8 años, no puede trabajar en locales que puedan perjudicar su desarrollo físico, psíquico, moral y social, o en horarios y lugares que le impidan la asistencia a la escuela; si el aprendiz está cursando enseñanza básica o media tiene una jornada máxima de seis horas, en las cuales están incluidas las de práctica.

La claridad, consistencia y coherencia de los acuerdos suscritos entre las partes de un contrato de aprendizaje son fundamentales: el contrato firmado entre la empresa y el aprendiz, el acuerdo entre la empresa y la institución de educación profesional y el programa de aprendizaje con especificación de la carga horaria de práctica en el empresa y la teórica en las aulas.

goo.gl/xTvZgH; senac, "Programa de Aprendizagem Profissional Comercial. Referenciais para a ação SENAC", (Serie de documentos técnicos, senac, Rio de Janeiro, diciembre de 2006), https://goo. gl/3pXzQb; y Ministério do Trabalho e Emprego, Manual da Aprendizagem: O que é preciso saber para contratar o aprendiz, 8. ${ }^{\mathrm{a}}$ ed. Revisada y ampliada (Brasilia: Assessoria de Comunicação do mte, 20I3), https://goo.gl/owcgto. 


\section{Programa de Acción "Me Encontrel"}

Es una estrategia sustentada en la articulación de políticas públicas de desarrollo social, educación y profesionalización en diferentes sectores productivos, que ofrece formación laboral, protección integral y empleo a adolescentes en situación de trabajo infantil, o en riesgo de ser víctima de las peores formas de trabajo infantil.El objetivo es generar oportunidades de formación para personas entre I4 y 77 años, mediante capacitación teórica y práctica, en asociación con el Sistema $\mathrm{S}^{27} \mathrm{y}$ otras instituciones autorizadas. Los jóvenes beneficiarios del programa son contratados por empresas como aprendices y, al mismo tiempo, son matriculados en cursos de aprendizaje, en instituciones reconocidas, responsables de la certificación.

El Programa está integrado por cuatro etapas:

\section{Planeación}

Formulación del diseño del plan de trabajo; la definición de los actores institucionales y de las políticas públicas que se pueden articular y el establecimiento de acuerdos para la gestión integral. En esta etapa es clave la coordinación con la secretaria estatal de educación para que los adolescentes sigan cursando o ingresen en la escuela pública, para garantizar su formación académica básica. Igualmente, es el momento de sensibilización con las empresas para asegurar el cumplimiento de la ley de aprendizaje y la contratación de los beneficiarios del Programa.

\section{Preparación}

Los adolescentes ingresan al Programa de diferentes modos:

- Por convocatoria específica de alguna empresa.

- Por el propio interés que los jóvenes demuestran de vincularse al Programa, en la oficinas de servicio social o en la entidad de formación.

- Por medio de contactos que establecen los servicios de asistencia social en las escuelas y comunidades. asistencia social, consultoría, investigación y asistencia técnica, que más allá de tener un nombre que inicia con la letra $S$, tienen raíces comunes y características organizacionales similares. Hacen parte del Sistema S: Servicio Nacional de Aprendizaje Industrial (senaI), Servicio Social del Comercio (sesc); Servicio Social de la Industria (sEsI) y Servicio Nacional de Aprendizaje del Comercio (sENAc). Existen además los siguientes: Servicio Nacional de Aprendizaje Rural (senar), Servicio Nacional de Aprendizaje de Cooperativismo (sEscoop) e Servicio Social de Transporte (sEST). 
- A través de la fiscalización que realizan los inspectores de trabajo, que retiran a los adolescentes del trabajo infantil y los invitan a participar en el Programa.

Identificado el posible beneficiario se establece contacto con los familiares para acompañarlos en todo el proceso; la secretaría de educación verifica que el adolescente está asistiendo a una institución educativa y toma las medidas indispensables para que su participación en el Programa no interfiera con la asistencia escolar; y, la superintendencia regional del trabajo sensibiliza a las empresas para que cumplan con la ley de aprendizaje y contraten a los adolescentes beneficiados.

\section{Implementación}

En esta instancia se define la articulación entre los diferentes actores y se lleva a cabo un monitoreo permanente para verificar el compromiso de las entidades participantes y se adoptan las medidas correctivas necesarias. La vinculación con la familia busca fortalecer los lazos afectivos, capacitación para el trabajo, apoyo en la búsqueda de empleo para los padres, la incorporación de otros miembros de la familia al Programa y el acceso a servicios de salud.

$\mathrm{Al}$ ingresar al programa, el adolescente suscribe un contrato de trabajo con la empresa y recibe un salario; el tiempo de formación es de un año, con [cuatro] meses de enseñanza en aula y [ocho] de práctica en las empresas, las que pueden prorrogar este plazo.

El proceso de profesionalización es implementado por el Sistema S o una entidad autorizada, durante el cual se refuerza la formación básica (portugués y matemáticas), con el objetivo de suplir las deficiencias escolares y enseñar nociones de sociabilidad empresarial.

\section{Control y evaluación}

Durante el proceso de formación se realizan sesiones de monitoreo formal para identificar las condiciones de vulnerabilidad del adolescente. Cuando termina la etapa de formación se verifican los efectos en la preparación del joven para la vida profesional, el fortalecimiento de las condiciones socioeconómicas de las familias y los conocimientos adquiridos ${ }^{28}$.

28 Tomado y modificado de senac, "Programa de Ação 'Me Encontrei' - Aprendizagem Profissional Comercial” (Cartilla, r. ${ }^{a}$ versión, Coordenação Especial de Projetos Estratégicos pela Promoção do Trabalho Decente no Ambito da Srte/Mt, Cuiabá, 20I4). 


\section{Servicio Nacional de Adiestramiento en Trabajo Industrial (SENATI), Perú}

Creado en 196r por iniciativa de la Sociedad Nacional de Industrias, es una persona jurídica de derecho público y de gestión privada, con reconocido liderazgo en la formación y aprendizaje dual y la FLT, que es facilitada a través de acuerdos entre el senaTi y las empresas, a través del "patrocinio".

El patrocinio de la empresa consiste en brindar las facilidades al alumno del sENATI, para el aprendizaje práctico en sus instalaciones productivas y otorgarle una asignación económica mensual no menor al 50\% de la Remuneración Mínima Vital.

Las empresas patrocinadoras son las que se encuentran inscritas en el Padrón General de Contribuyentes del senati y pagan sus aportes mensuales (o,75\% sobre las remuneraciones totales), como también las no inscritas en tal padrón, o voluntarias, siempre y cuando hayan aportado tres pagos mensuales mínimos consecutivos, previos a la solicitud del patrocinio. Los programas que pueden tener patrocinados son:

- Dual. Forma técnicos operativos para el desempeño de ocupaciones o especialidades propias de la actividad industrial manufacturera, así como de las labores de instalación, reparación y mantenimiento realizadas en las demás actividades económicas. Este programa de aprendizaje se caracteriza por efectuar la mayor parte del aprendizaje práctico dentro de la empresa, en labores propias del establecimiento. A la vez que los aprendices ganan experiencia laboral, contribuyen en los procesos productivos.

- $\quad$ Calificación de trabajadores en servicio (CTS). Proceso flexible que considera la ocupación integrada por módulos ocupacionales de corta duración con salidas parciales, ofreciendo a los participantes la posibilidad de insertarse en el mercado laboral y continuar el proceso de capacitación en cualquier momento.

- Administradores industriales modalidad dual. Imparte formación profesional para el desempeño de funciones administrativas en la empresa industrial, desarrollando competencias para el dominio de aspectos de gestión de materiales, administración de la producción, contabilidad y costos, así como administración de personal y ventas. Las actividades de formación se alternan en un centro del seNATI y en la empresa, el aprendiz está vinculado con un contrato de aprendizaje con el empleador.

- Capacitación continua. Se realiza mediante seminarios, talleres o conferencias de corta duración. 


\section{Centro Tecnológico de Textiles y Confecciones (CTTC)}

A través del ctTc, el sENaTi presta servicios técnicos de laboratorios, investigación y desarrollo y asesoría especializada a las empresas de los sectores textil y confecciones.

La FLT está dirigida a los patrocinados, quienes en el área textil desarrollan destrezas y habilidades operativas o productivas y conocimientos tecnológicos de los procesos acordes con las exigencias de calidad. Así mismo, adquieren conocimientos tecnológicos específicos y complementarios, relacionados con las matemáticas, física, dibujo técnico, seguridad industrial, comunicación oral o escrita, inglés técnico e informática; al mismo tiempo que adquieren capacidades polifuncionales, acordes con las exigencias de la actividad productiva industrial para conducirse con autonomía en un puesto de trabajo.

En el área de confecciones la FLT se propone el desarrollo de prototipos y la documentación de las especificaciones técnicas desde las características del tejido, hasta el acabado de la prenda, aplicando especificaciones y normas técnicas. Se hace énfasis en el diseño de prendas cuya reproducción sea viable y acorde con los procesos productivos y recursos disponibles de las empresas, para lograr que los mismos sean competitivos en el mercado.

Las carreras técnicas que se realizan en la Escuela de Confecciones son: Confeccionista de Prendas de Vestir y Mecánico de Máquinas de Confección de Prendas de Vestir. En la Escuela Textil son: Mecánico Textil en Tejeduría Plana, Mecánico Textil en Género de Punto, Mecánico Textil en Hilandería, Controlista de Calidad Textil, Técnico Profesional en Química Textil y Técnico Profesional en Procesos de Producción Textil ${ }^{29}$.

\section{Algunas definiciones del CONTRATO de APRENDIZAJE}

\section{ARgentinA, LeY 26390 dE 2008}

El contrato de aprendizaje tendrá finalidad formativa teórico-práctica, la que será descripta con precisión en un programa adecuado al plazo de duración del contrato. Se celebrará por escrito entre un empleador y un joven sin empleo, de entre dieciséis (I6) y veintiocho (28) años... Este contrato tendrá una duración mínima de tres (3) meses y una máxima de un (I) año... A la finalización del contrato el empleador deberá entregar al aprendiz un certificado suscripto por el responsable legal de la empresa, que acredite la experiencia o especialidad adquirida... ${ }^{30}$.

Cfr. "Centro Tecnológico Textil Confecciones (сттс)", consultado en septiembre de 20r6, https:// goo.gl/QrNVOp. 


\section{BRASIL, LEY 11180 DE 2005}

Contrato de aprendizaje es un contrato de trabajo especial, celebrado por escrito y por plazo determinado, en el que un empleador se compromete a asegurar a un mayor de I4 y menor de 24 años inscrito en un programa de aprendizaje formación técnico profesional metódica, compatible con su desarrollo físico, moral y psicológico, y un aprendiz, a ejecutar con cuidado y diligencia las tareas necesarias para esa formación ${ }^{31}$.

\section{Chile, artículos 78 y siguientes del Código del Trabajo}

Contrato de trabajo de aprendizaje es la convención en virtud de la cual un empleador se obliga a impartir a un aprendiz, por si o a través de un tercero, en un tiempo y en condiciones determinados, los conocimientos y habilidades de un oficio calificado, según un programa establecido, y el aprendiz a cumplirlo y a trabajar mediante una remuneración convenid... ${ }^{32}$. Sólo podrán celebrar contrato de aprendizaje los trabajadores menores de veintiún años de edad... ${ }^{33}$. El contrato... tendrá vigencia hasta la terminación del plan de aprendizaje, el que no podrá exceder de dos años... ${ }^{34}$.

\section{PeRÚ, LeY 28518 DE 2005}

El aprendizaje es una modalidad que se caracteriza por realizar parte del proceso formativo en la unidades productivas de las empresas, previa formación inicial y complementación en un Centro de Formación Profesional autorizado para desarrollar la actividad de formación profesional... ${ }^{35}$. El Convenio de Aprendizaje es un acuerdo de voluntades, responsabilidades y obligaciones celebrado entre la empresa, el Centro de Formación Profesional y el aprendiz. Pueden celebrar Convenios de Aprendizaje las personas mayores de I4 años, siempre que acrediten como mínimo haber concluido sus estudios primarios ${ }^{36}$.

3 I Brasil, Ley i i 80 del 23 de septiembre de 2005, sobre la concesión de becas de permanencia a estudiantes beneficiarios del Programa Universidad para Todos (Prouni), art. 428.

32 Chile, Código del Trabajo, art. 78.

33 Ibíd., art. 79.

34 Ibíd., art. 84.

35 Perú, Ley 285 I 8 de 2005 , sobre modalidades formativas laborales, cap. II, art. 5 .

36 Ibíd., art. 7 .

[ 192 ] Vol 1 • n. ${ }^{\circ} 1$ enero-junio $2017 \cdot$ pp. 167-210 


\section{Colombia, Ley 789 de 2002 y Ley 1450 de 2011}

Estas leyes reafirmaron la característica propia del contrato de aprendizaje e introdujeron modificaciones sustanciales al mismo ampliando su ámbito al incorporar las prácticas con estudiantes universitarios, técnicos o tecnólogos, así como aquellas de formación empresarial en los lugares de trabajo.

El contrato de aprendizaje es una forma especial dentro del Derecho Laboral, mediante la cual una persona desarrolla formación teórica práctica en una entidad autorizada, a cambio de que una empresa patrocinadora proporcione los medios para adquirir formación metódica y completa requerida en el oficio, actividad u ocupación y esto le implique desempeñarse dentro del manejo administrativo, operativo comercial o financiero propios del giro ordinario de las actividades de la empresa, por cualquier tiempo determinado no superior a dos (2) años, y por esto reciba un apoyo de sostenimiento mensual, el cual en ningún caso constituye salario... Son elementos particulares y especiales del contrato de aprendizaje:

- La finalidad es la de facilitar la formación de las ocupaciones en las que se refiere el presente artículo;

- La subordinación está referida exclusivamente a las actividades propias del aprendizaje;

- La formación se recibe a título estrictamente personal;

- El apoyo de sostenimiento mensual tiene como fin garantizar el proceso de aprendizaje.

Durante toda la vigencia de la relación, el aprendiz recibirá de la empresa un apoyo de sostenimiento mensual que sea como mínimo en la fase lectiva el equivalente al 50\% de un (I) salario mínimo mensual vigente... El apoyo de sostenimiento durante la fase práctica será equivalente al $75 \%$ de un salario mínimo legal mensual vigente... ${ }^{37}$. La ley 789 fue expedida para promover la empleabilidad y desarrollar la protección social, haciendo un... ajuste de las disposiciones que regulan las relaciones laborales en el país con el propósito de aliviar la situación que viven los desempleados y mejorar el ambiente laboral en aras a lograr elevar los niveles de productividad ${ }^{8}$.

Las leyes referidas son enfáticas al prever que el contrato de aprendizaje es de naturaleza especial y que los emolumentos que entrega la empresa al aprendiz

37 Ley 789 de 2002 , sobre el apoyo al empleo y la ampliación de la protección social, art. 30.

$3^{8} \quad$ Cfr. Exposición de motivos de la Ley 789 de 2002. 
no son salario en ningún caso, los mismos que tampoco pueden ser regulados a través de convenios o contratos colectivos o fallos arbitrales.

Todas las empresas privadas, las estatales y las de economía mixta, que realicen cualquier tipo de actividad económica diferente a la construcción y que ocupan más de quince ( I $_{5}$ ) trabajadores, están obligadas a vincular aprendices: las que tengan entre quince ( $\mathrm{I}_{5}$ ) y veinte (2O) trabajadores, un (I) aprendiz y las de más de veinte (20) trabajadores, un aprendiz por cada veinte (20) y uno adicional por fracción de diez (Iо) ${ }^{39}$ “... corresponde a las empresas seleccionar los oficios y ocupaciones objeto de contrato de aprendizaje así como las modalidades y los postulantes para los mismos"4.

"La etapa lectiva o de formación profesional integral podrá ser realizada en el SENA, en instituciones educativas o especializadas reconocidas por el Estado, o directamente en la empresa previa autorización del SENA"4r.

La formación que imparte directamente la empresa o FLT debe ser autorizada por el SENA, cumpliendo con las siguientes condiciones:

- Ofrecer un contenido de formación lectiva y práctica acorde con las necesidades de la formación profesional integral y del mercado de trabajo.

- Disponer de recursos humanos calificados en las áreas en que ejecuten los programas de formación profesional integral.

- Garantizar, directamente o a través de convenios con terceros, los recursos técnicos, pedagógicos y administrativos que garanticen su adecuada implementación. ${ }^{42}$

La empresa y la entidad de formación podrán determinar la duración de la etapa productiva (FLT), al igual que su alternancia con la lectiva.

Desde el punto de vista legal, ha habido una apertura para armonizar el aprendizaje y la FLT a nuevas situaciones de las personas, las empresas y el mercado de trabajo, en general. No obstante, para Colombia es urgente que el sENA mejore la calidad de la formación, puesto que los resultados de los aprendices del SENA en competencias genéricas son inferiores a los de sus pares en instituciones de educación superior y de pregrado universitario ${ }^{43}$. 


\section{FORMACIÓN DUAL SENA}

En 2OI4 el SENA inició un programa piloto para aplicar el modelo de enseñanza dual, en el cual los aprendices alternan su proceso de formación en los ambientes de aprendizaje propios del sENA y la empresa con la que laboran.

Las empresas y el SENA definen las ocupaciones y los perfiles laborales requeridos, identifican las necesidades de formación y participan tanto en la elaboración de los diseños de los programas como en el proceso de selección de los aspirantes. El sENA también se encarga de ejecutar el proceso de administración educativa, acompañar y formar a los tutores de la empresa en temas de pedagogía y certificar la formación.

El piloto empezó con cinco empresas: General Motors, Samsung, Cerrejón, Fiza y Procter \& Gamble, en diferentes ocupaciones: pintura, ensamble, asistencia administrativa, operación de camión minero, mantenimiento mecánico, mantenimiento eléctrico, soporte técnico en líneas de producto como Internet móvil y aire acondicionado ${ }^{44}$.

\section{BRECHA DE COMPETENCIAS EN EL MERCADO DE tRABAJO}

La encuesta sobre escasez de talento de Manpower Group, que se realiza desde el 2006 y que en su versión de 2013 consideró a más de 38600 empleadores en 42 países, incluidos ocho latinoamericanos, reportó que el $35 \%$ de las empresas a nivel mundial tuvo dificultades para llenar las posiciones de trabajo ofrecidas como resultado de la falta de candidatos adecuados... Las dificultades de contratación de personal son un problema global, y América Latina lo experimenta al igual que el resto del mundo... La falta de competencias técnicas y de experiencia está entre las razones más nombradas por las cuales las empresas tuvieron problemas de contratación de personal... Los resultados anteriores son consistentes con datos del Banco Mundial, [a 2oro, según los cuales] el 35,8\% de las empresas manufactureras en América Latina y el Caribe consideran que la inadecuada formación de la fuerza laboral es un [obstáculo] para la operación de las empresas ${ }^{45}$.

La falta de pertinencia es uno de los puntos más débiles de los sistemas de capacitación de América Latina; la respuesta a la demanda de competencias que requiere el sector productivo tiene que tener en cuenta las características, dificul-

44 Cfr. "Desde hoy, el sena implementa sistema dual de aprendizaje", Sala de Prensa, Portal Web SENA, 26 de junio de 20I4, https://goo.gl/uzsHFi.

Juan José Llisterri et al., "Educación técnica y formación profesional en América Latina: el reto de la productividad” (Documento oficial, Serie Políticas Públicas y Transformación Productiva, núm. I3, CAF), 25 . 
tades y transformaciones de procesos, tanto administrativos como tecnológicos, así como el análisis de contenidos de los programas de formación. Es fundamental, igualmente, que se realicen evaluaciones de impacto de la formación para el trabajo que permita identificar si las inversiones han dado resultados positivos, cualitativos y cuantitativos, tanto en la inserción y movilidad de quienes se capacitan, como en la productividad de las empresas.

\section{LA IDENTIFICACIÓN ANTICIPADA DE LAS COMPETENCIAS LABORALES}

La resolución relativa a las calificaciones para la mejora de la productividad, el crecimiento del empleo y el desarrollo ${ }^{46}$, plantea que el desequilibrio entre la oferta y demanda de calificaciones tiene elevados costos económicos y sociales y es la consecuencia del desempleo estructural y al mismo tiempo contribuye a él. La identificación temprana de las necesidades actuales y futuras de competencias profesionales forma parte de las estrategias orientadas para reducir dicho desajuste. En consecuencia, permite:

- Ajustar los programas de la educación inicial a las necesidades actuales y futuras.

- Prever las necesidades de calificaciones actuales, a mediano y largo plazo, para asegurar una mayor correspondencia entre los empleos, las ocupaciones y las calificaciones.

- $\quad$ Proporcionar a todas las partes interesadas, en particular a los trabajadores desplazados y a los que buscan mejores oportunidades de trabajo, la información adecuada para pasar de los sectores en declive a los que están en auge.

- Apoyar a las personas jóvenes a basar sus elecciones en materia de formación en perspectivas de empleo realistas.

- Facilitar decisiones mejor informadas respecto de inversiones en la formación y el aprendizaje permanente por los empleadores y los trabajadores.

- Contribuir con las empresas en materia de innovación y adopción de nuevas tecnologías, mediante la posibilidad oportuna de trabajadores calificados apropiadamente, el perfeccionamiento de competencias y la ayuda a éstos para que sigan siendo aptos para el empleo.

Las proyecciones cualitativas y cuantitativas se deben relacionar con estrategias nacionales definidas ampliamente, por lo que es necesario analizar los sectores y regiones con alto potencial de crecimiento, a fin de identificar las nuevas posibilidades de empleo y sus exigencias en cuanto a capacitación, así

\footnotetext{
46 Organización Internacional del Trabajo, "Calificaciones para la mejora de la productividad, el crecimiento del empleo y el desarrollo" (Informe v, quinto punto del orden del día, Conferencia Internacional del Trabajo, 97. ${ }^{\mathrm{a}}$ reunión, ort, 2008).
} 
como los sectores tradicionales en descenso y los perfiles de competencias de las personas que pierden sus empleos, tanto como la calidad de la oferta de formación. Además, el análisis de las necesidades de calificaciones debe abarcar las competencias básicas y técnicas, puesto que estas cambian en función del crecimiento económico.

La prospectiva ocupacional analiza las necesidades de formación para asegurar su adecuación con los requerimientos de los sectores productivos; se basa en la observación del mercado de trabajo, la identificación y definición de las competencias, así como el análisis de las tendencias sociales, económicas y tecnológicas.

\section{El Modelo SenAl de Prospectiva}

El Servicio Nacional de Aprendizaje Industrial de Brasil-senai ha desarrollado el Modelo de Prospectiva ${ }^{47}$, que permite anticipar las demandas de competencias profesionales, el cual está basado en diversos tipos de análisis: tecnológicos, organizacionales, de ocupaciones emergentes, de impacto, de tendencias ocupacionales, de formación profesional comparada y de antenas temáticas, fundamentalmente. Para efectuar estos estudios, el SENAI se vincula con diferentes interlocutores: universidades, empresas, centros de ciencia y tecnología, especialistas sectoriales, cámaras de industria, entre otros. La prospectiva SENAI permite tener un panorama completo del contexto educativo, tecnológico y ocupacional.

Los resultados del modelo posibilitan una mejor preparación del SENAI en la formación de mano de obra, disminuyendo los efectos negativos que acarrea su ausencia. Por otra parte, la previsión de posibles cambios en los sectores industriales estudiados permite generar una serie de servicios tecnológicos, lo que contribuye a aumentar la competitividad de las empresas brasileñas. La aplicación del Modelo requiere la participación de tres equipos de trabajo:

Grupo Ejecutor. Constituido por especialistas sectoriales, cuyo objetivo es orientar técnicamente los estudios para el sector referido. Entre sus atribuciones se pueden citar:

- Elección, descripción y aprobación de las tecnologías y ocupaciones que se incluirán en los cuestionarios Delphi.

- Elección y aprobación de las listas de especialistas que conformarán los paneles Delphi.

- Validación de resultados de las prospecciones tecnológicas y organizativas;

- Elaboración de las recomendaciones. 
El Grupo Ejecutor puede constituirse por: dos especialistas externos, del ámbito empresarial o académico; dos consultores sectoriales externos, también responsables por el estudio sectorial en las dimensiones tecnológicas y ocupacional; cuatro especialistas de la institución de formación profesional, procedentes de unidades especializadas en planificación de la formación o en el área sectorial bajo estudio.

Paneles Delphi y de Especialistas. Grupo formado por expertos sectoriales que tratan de identificar las tendencias de difusión tecnológica en un período de cinco a diez años.

Especialistas sectoriales. Grupo que aporta su conocimiento en la investigación de impactos ocupaciones.

Las etapas del Modelo son: tendencias de difusión tecnológica (prospección tecnológica y organizacional); análisis de ocupaciones emergentes; investigación de impactos ocupacionales; análisis de tendencias ocupacionales; análisis de brechas educativas; recomendaciones y monitoreo.

Respondiendo a solicitudes de las instituciones de formación profesional de la Red oit-Cinterfor, en mayo de 20 I 2 se inició un proceso de Cooperación Sur-Sur para transferir y adaptar el modelo SENAI a varios países, trabajando con las respectivas entidades y actores sociales relevantes: Instituto Nacional de Aprendizaje (INA) en Costa Rica; Instituto Salvadoreño de Formación Profesional (INSAForp) en El Salvador; Instituto Técnico de Capacitación y Productividad (INTECAP) en Guatemala; Instituto Nacional de Formación Profesional y Capacitación para el Desarrollo Humano (INADEH) en Panamá e Instituto de Formación Técnico Profesional (Infotep) en República Dominicana. Tal proceso duró catorce meses y tuvo como resultados estudios prospectivos en la construcción y el turismo, así como el fortalecimiento de las instituciones y de los interlocutores sociales participantes, la identificación de competencias y la definición de los currículos respectivos ${ }^{48}$.

Desde 2004 el modelo se ha aplicado en más de diez sectores en Brasil, entre los cuales destacan: textil, petroquímico, máquinas y equipos, telecomunicaciones, construcción, calzado, alimentos (carnes), fundición, construcción y reparación de embarcaciones, y automatización industrial. Así mismo, se han realizado más de 170 publicaciones dirigidas a orientar a diversos grupos de interés, incluidos gestores, técnicos y docentes de instituciones de formación profesional.

Gracias a la cooperación técnica del senai este Modelo puede ser un referente importante para reducir el desajuste entre demanda y oferta de competen-

\footnotetext{
48 Red de Instituciones de Formación Profesional, "Anticipación de las competencias profesionales. Transferencia del Modelo senar de Prospectiva" (Documento de trabajo, Montevideo, oIT y Cinterfor, 20I3), https://goo.gl/O2JuHC.
} 
cias laborales, contribuyendo a mejorar la gestión de las instituciones encargadas de la formación para el trabajo, disminuir el desempleo estructural y promover la mejora de la productividad laboral y competitividad de los países.

\section{Productividad laboral y desarrollo de los ReCursos humanos}

La Conferencia Internacional del Trabajo (CIT) ha puesto de relieve, en diversas oportunidades, la necesidad de incrementar la productividad laboral, entre otras en las conclusiones sobre las calificaciones para la mejora de la productividad, el crecimiento del empleo y el desarrollo: “... La mejora de la productividad no es un fin en sí misma, sino un medio para mejorar la vida de los trabajadores, la sostenibilidad de las empresas, la cohesión social y el desarrollo económico. La mejora continua de la productividad también es una condición para la competitividad y el crecimiento económico..."49.

Las conclusiones expresan que una economía basada en bajas calificaciones, baja productividad y bajos salarios es insostenible a largo plazo e incompatible con la reducción de la pobreza. Representa el círculo vicioso formado por la educación insuficiente, la falta de capacitación, la baja productividad y el trabajo de poca calidad y mal remunerado, que atrapa a los trabajadores pobres y margina a los que no poseen las calificaciones necesarias del proceso de crecimiento económico y desarrollo social. Esto también afecta negativamente a la competitividad de las empresas y a su capacidad para contribuir al desarrollo económico y social.

En cambio, las estrategias basadas en facilitar el acceso a la educación y capacitación de mejor calidad puede conformar un círculo virtuoso en cuyo contexto el incremento de las competencias favorezca la innovación, el incremento de la productividad y el desarrollo empresarial, el cambio tecnológico, la inversión, la diversificación de la economía y la competitividad, que son elementos necesarios para mantener y acelerar la creación de más y mejores empleos.

Respecto de América Latina y el Caribe ha habido una gran preocupación desde hace varios años, por cuanto:

Un problema capital —especialmente para los mercados de trabajo de la regiónreside en que, en las últimas décadas, este indicador de productividad [PIB] no creció en muchos países, al punto que la cifra media es hoy bastante similar a aquella registrada en la región a inicios del decenio de los ochenta. El producto por trabajador —o productividad del trabajo— es un elemento determinante para 
el progreso económico y social, tal como se señaló en [el informe sobre el empleo en el mundo de la ort del año 2004], pues es un mecanismo de transmisión importante entre el mundo de la producción y el mercado de trabajo. Su estancamiento en el valor de hace dos decenios explica también por qué las tasas de pobreza actuales en la región también son bastante similares a las observadas a inicios de los años ochenta... ${ }^{\circ}$.

$\mathrm{Al}$ analizar la evolución de la productividad laboral tras el impacto de la reciente crisis financiera internacional, la CEPAL y la oIT concluyen que el aumento de la productividad ha sido muy modesto, tanto en términos absolutos como relativos y que su incremento continuo es necesario para obtener mejoras sostenibles de las condiciones de vida de la población ${ }^{51}$.

Son numerosas las investigaciones que se han realizado en la región respecto de la relación entre la productividad laboral y la formación para el trabajo, todas coinciden en que es indispensable mejorar la calidad, la pertinencia y la cobertura de la educación y fortalecer la formación profesional y la capacitación de los trabajadores para, entre otros aspectos, aprovechar los mayores niveles de inversión y las nuevas tecnologías. Igualmente, el crecimiento económico no sólo incide en la mayor generación de empleo, sino también en una demanda diferenciada de calificaciones, habilidades y conocimientos e influye en las condiciones laborales de diferentes grupos de trabajadores.

A su vez, la productividad laboral debe influir en la generación de mejores empleos y beneficios salariales y no salariales para los trabajadores; una alta productividad tiende a favorecer de manera directa la existencia de empleos de buena calidad, mientras que una baja productividad suele conllevar procesos de exclusión del empleo productivo ${ }^{52}$.

\section{EL DESAFÍO DE MEJORAR LA PRODUCTIVIDAD DE MICRO, PEQUEÑAS Y MEDIANAS EMPRESAS}

Las pyme son agentes económicos clave, ya que buena parte de la población y de la economía dependen de su actividad y desempeño. Las pyme en América Latina y el Caribe representan aproximadamente el 99\% del total de las empresas, generan una gran parte del empleo (67\%) y actúan en una amplia variedad de ámbitos de la producción y de los servicios. A pesar de los programas de apoyo

$50 \quad$ Organización Internacional del Trabajo (оIт), “Trabajo Decente en las Américas: Una agenda hemisférica, 2006-20 5" (Informe del director general sobre la XVI Reunión Regional Americana, Brasilia, mayo de 2006), I, https://goo.gl/2yJYuV.

5 I Cfr. cepal/ort, “Coyuntura laboral en América Latina y el Caribe” (Documento, mayo de 20I2).

52 Cfr. Jürgen Weller, "Aspectos de la evolución reciente de los mercados laborales de América Latina y el Caribe", Revista CEPAL, núm. I I4 (diciembre de 2014): 7-29. 
que se llevan a cabo en los países para mejorar su desempeño, fomentar su desarrollo productivo y generar un ambiente de negocios favorable, los resultados no han cumplido con las expectativas y no se han observado mejoras significativas en la productividad y la competitividad de estas empresas ${ }^{53}$. Tales rezagos son ocasionados por la notoria heterogeneidad estructural de las economías de la región, donde coexisten sectores y empresas con marcadas diferencias de productividad que reflejan, entre otros aspectos, un amplio mosaico de brechas: de habilidades, competencias y conocimientos, de incorporación de progreso técnico, de movilidad laboral ascendente, entre otras.

Son varios los aspectos de política que deben considerarse para promover la mejorar de la productividad de las pyme, tales como financiamiento, innovación y acceso a nuevas tecnologías, articulación productiva en conglomerados y capital humano, tema éste al que se hará referencia a continuación.

\section{Capital humano en las PyME}

La baja productividad de estas empresas se puede explicar por múltiples factores, entre los cuales se encuentran: el acceso, cobertura, calidad y años de escolaridad que tienen las personas, así como el desajuste entre la formación que provee el sistema educativo y las que demanda el sector productivo, que si bien afecta a todos los países y al sector productivo en general, como se ha señalado en páginas anteriores, es particularmente crítico tratándose de las pyme.

En cuanto a los años de escolaridad, el 75,9\% de los ocupados en las pyme alcanzan como máximo la enseñanza secundaria incompleta: $57 \%$ en Argentina, 5 I \% en Chile, $38 \%$ en México y $40 \%$ en Perú ${ }^{54}$. Por otra parte, el abandono escolar tiene un impacto negativo en el nivel educativo de quienes se incorporan al mercado de trabajo, generalmente en el sector informal donde la presencia de estas empresas es mayor. Otro ámbito relevante es el nivel de competencias de los empresarios; en general, hay carencias importantes de capacidades en materia de gestión y liderazgo empresarial, lo que impide encarar procesos de desarrollo, de incorporación de tecnologías, de innovación o de apertura a nuevos sectores y mercados, lo que implica una barrera para el incremento de la productividad.

53 Cfr. CePAl y AL-INvest, "Cómo mejorar la competitividad de las pymes en la Unión Europea y América Latina y el Caribe: propuestas de política del sector privado" (Documento institucional, CEPAL, ALINVEST, 2OI3).

Marco Tueros, et al., "Crisis internacional y políticas para las mipymes: desafíos y oportunidades para América Latina y Europa" (Documento realizado en ocasión del seminario "Crisis Internacional y Políticas para las mipymes", Santiago de Chile, I 3 y I4 de octubre de 2009). 


\section{Productividad laboral y capital humano en Colombia}

De acuerdo con estudios del BID, Colombia es el segundo país de la región con la más baja productividad laboral, adolece de una brecha de habilidades, la formación para el trabajo es precaria y debe ser complementada con herramientas para el trabajo. Los 2 I millones de trabajadores colombianos con empleo se sienten agobiados con extensas jornadas laborales y, por lo general, tienen una pesada carga de actividades por cumplir. Sin embargo, el esfuerzo no coincide con la productividad del país, que ocupó el puesto 66 entre I44 países, tras la más reciente medición realizada por el Foro Económico Mundial.

Según el Consejo Privado de Competitividad (CPP) en Colombia se necesitan 4,5 trabajadores para realizar la misma actividad laboral que hace un solo empleado estadounidense y, pese a un buen desempeño económico entre $2000 \mathrm{y}$ 2013 , cuando el pIB pasó de 6700 USD a I 2400 usD y el nivel de inversión de I4\% a $24 \%$ del PIB, el país está lejos de alcanzar el objetivo que fijó el Sistema Nacional de Competitividad e Innovación en 2006, de ser la tercera economía más competitiva en la región en el 2032 en la medición del Índice Global de Competitividad del Foro Económico Mundial. Igualmente expresa que la productividad de la economía colombiana no ha crecido en sintonía con los mayores niveles de inversión y que, aunque ha habido un aumento de la productividad laboral en los últimos Io años, pasando de I 7 O0O UsD por trabajador en el año 2000 a 20 OOO USD en 2013 , actualmente Colombia tan solo supera marginalmente a Brasil y está significativamente por debajo de países como México y Chile 55 .

El Consejo Privado de Competitividad en numerosos foros y amplias investigaciones ha planteado la necesidad de organizar los esfuerzos en materia de política de desarrollo productivo; uno de tales esfuerzos se refiere a desarrollo de habilidades y competencias del capital humano. En efecto, el Consejo expresa que la escasez de capital humano de calidad, pertinente y suficiente es uno de los principales cuellos de botella que limitan el proceso de transformación productiva del país, percibido particularmente por aquellos que lideran los trabajos sobre apuestas productivas o iniciativas cluster, en la medida en que no existe $-\mathrm{o}$ es insuficiente- el capital humano requerido para lograr que sus sectores transiten del punto en el que se encuentran actualmente hacia segmentos de negocio de mayor productividad.

Destaca el Consejo que un estudio realizado por Manpower Group ${ }^{56}$, el $57 \%$ de las empresas encuestadas reportó dificultades a la hora de encontrar el talento humano adecuado para cubrir sus vacantes. La gran mayoría de estas

55 Consejo Privado de Competitividad, "Informe Nacional de Competitividad 2014-201 5”, 26.

56 ManpowerGroup, "ManpowerGroup Annual Talent Shortage Survey” (Encuesta, ManpowerGroup, 2OI4). 
acusó la falta de competencias técnicas (específicas) en los aspirantes como la principal causa del problema. Adicionalmente, según el Banco Interamericano de Desarrollo (віD), Colombia es el país de la región que más invierte en formación para el trabajo como porcentaje del PIB; sin embargo, su productividad laboral es una de las más bajas.

Aunque la falta de pertinencia de la formación no es problema exclusivo de Colombia puesto que igualmente aqueja a economías aún más desarrolladas, el país enfrenta el reto de garantizar una formación pertinente, flexible y oportuna, que logre atender las necesidades cambiantes del sector productivo. A propósito el Consejo plantea la realización de esfuerzos transversales a todos los sectores para que las empresas cuenten con suficientes personas con las competencias (básicas y específicas) requeridas, con un nivel de logro satisfactorio y en el momento adecuado, para garantizar su competitividad. A continuación se transcriben:

\section{Promover programas de formación a LA MEDIDA PARA EMPRESAS}

Mayor número de esquemas que busquen dar respuesta inmediata a demandas puntuales en materia de capital humano del sector privado y se materialicen a través de pactos por el trabajo entre empresas e instituciones de formación, como son las Alianzas para el Trabajo del sena. Dichos pactos resultan en el entrenamiento en competencias específicas para el desempeño de una labor puntual, asegurando un empleo al finalizar el período formativo. Por lo general, la formación requerida es de corta duración y se justifica la creación del programa, en la medida en que sea para un número significativo de personas. Aunque los programas deben servir, en principio, para cualquier sector de la economía, las iniciativas cluster, por reunir a varias empresas y trabajadores, son candidatas óptimas para recibirlos.

\section{REFORMAR CURRÍCULOS DE FORMACIÓN TÉCNICA Y TECNOLÓGICA (TYT) Y FORMACIÓN PARA EL TRABAJO Y EL DESARROLLO HUMANO (FTDH) PARA QUE INCLUYAN COMPETENCIAS BÁSICAS O TRANSVERSALES}

A partir de recomendaciones de OCDED-CEPAL para mejorar el capital humano se trata de garantizar que las competencias básicas del siglo xxi se formen no solo en la formación universitaria, sino también en la formación TyT y en la FTDH. En efecto, una parte importante de las brechas de capital humano que adolecen los empresarios está asociada a las deficiencias en este tipo de competencias. De esta manera, competencias básicas como la lectura crítica, el razonamiento cuantitativo, la escritura, el dominio de las Tic, el dominio de un segundo idioma, entre otras, deberían hacer parte de los currículos de toda formación postsecundaria. 


\section{Fomentar la UtILIZACIÓN DE LAS UNIDADES VocaCIONALES de Aprendizaje en la Empresa (UVAE)}

Las UVAE son los espacios formativos dentro de las empresas, creadas para formar y capacitar a los trabajadores para el desempeño de las diferentes funciones relacionadas con los procesos técnicos de las empresas. En esta capacitación el Gobierno asume un rol de acreditador y promotor aportando recursos.

Contar con un capital humano que apalanque el proceso de transformación productiva no solo dependerá de tener programas de formación relevantes, sino también de que el país logre cambiar sus modelos mentales frente a ciertos paradigmas que hoy en día limitan este proceso; algunos instrumentos que apuntan a este objetivo, son:

- Formar competencias en innovación, emprendimiento y creatividad en todo nivel. El Consejo plantea la importancia de la formación en competencias de liderazgo, gestión de la innovación, emprendimiento y creatividad fundamentales en una política de capital humano para el desarrollo productivo, aunado a los esfuerzos para incluir la educación económica y financiera dentro del currículo de educación básica y media.

- Cambiar la valoración social de la formación TyT y la FTDH. La formación TyT y la FTDH han sido históricamente menospreciadas por la sociedad colombiana. Este tipo de formación está valorada como una educación de menor nivel a la del pregrado universitario, en lugar de considerarse como complementaria. Lo anterior lleva a que el país deba implementar acciones simultáneas para cambiar tal percepción, en particular cuando una parte sustancial de las brechas de capital humano del país se podrían cerrar a partir de este tipo de formación.

- Cambiar la valoración social del fracaso y del emprendimiento. Más allá del difícil acceso al sistema financiero y otras limitantes al emprendimiento, debe trabajarse en temas de mentalidad y cultura del emprendimiento. El miedo al fracaso, la aversión al riesgo y el imaginario de que el colombiano debe formarse para trabajar y no para emprender sus propias iniciativas, puede y debe transformarse.

\section{Capital humano para la Investigación y Desarrollo (l+D)}

El Consejo plantea la necesidad de ampliar y consolidar instrumentos específicos para fortalecer el acceso a capital humano que lidere y apoye procesos de I+D. Las propuestas asociadas con tal propósito son: 


\section{Programas de becas y CRÉdtos Condonables para PhD y Maestría}

Los esfuerzos que viene realizando el país, a través de Colciencias, son insuficientes. Los mismos, además de ampliarse deben articularse con las propuestas productivas de los niveles nacional, departamental y sectorial en el marco de la PDP.

\section{Politica migratoria integral que apunte a atraer capital humano altamente CALIFICADO PARA LA I+D}

Una política migratoria integral en el marco de la PDP debe apuntar a atraer capital humano altamente calificado, nacional o foráneo, del extranjero, a través de la flexibilización y la simplificación de requisitos para la obtención de visas de trabajo y del otorgamiento de un paquete atractivo de incentivos. Si bien el país viene haciendo algunos esfuerzos en tal sentido, como es el programa "Es Tiempo de Volver" de Colciencias, los mismos deben ser ampliados y asociados con las apuestas productivas del país.

\section{FOMENTAR LA VINCULACIÓN DE INVESTIGADORES CON DOCTORADO Y MAESTRÍA EN EL SECTOR PRODUCTIVO}

Además de generar investigación relevante desde centros tecnológicos y de $\mathrm{I}+\mathrm{D}$, es clave fortalecer la capacidad de investigación en las empresas. Los bonos de reinserción en empresas, por ejemplo, son mecanismos para incentivar la contratación de investigadores con doctorado y maestría por parte de estas.

\section{INCREMENTAR EL NÚMERO DE AMBIENTES ESPECIALIZADOS PARA LA APROPIACIÓN DE INNOVACIÓN Y TECNOLOGÍA Y LA FORMACIÓN}

Iniciativas como los Tecnoparques del senA deben fortalecerse y ampliarse en cuanto facilitan el desarrollo de proyectos innovadores de base tecnológica, en los cuales también se lleva a cabo el proceso de formación. En estos ambientes se debe garantizar la apropiación, difusión, adaptación y transferencia tecnológica desde y hacia el sector productivo, a través de asesoría técnica, generación y difusión de conocimiento y dotación de infraestructura física y tecnológica de laboratorios.

\section{IDENTIFICAR Y ABORDAR NECESIDADES DE CAPITAL HUMANO EN APUESTAS PRODUCTIVAS}

La sola identificación de perfiles y competencias requeridas en un sector o industria, sumada al análisis de la oferta que permite la caracterización de bre- 
chas, es costosa en términos de tiempo y recursos. Si bien existen iniciativas como la Red de Observatorios del Mercado de Trabajo (ormet), coordinada desde el Ministerio de Trabajo, las mesas sectoriales del sena o el trabajo del de Eafity Proantioquia para cuatro clusters en Medellín, las mismas son insuficientes y desarticuladas frente a los desafíos que plantea el desarrollo productivo del país.

\section{Priorizar la construcción del Sistema Nacional de Calificaciones EN SECTORES AFINES A LAS APUESTAS PRODUCTIVAS BAJO LA PDP}

La Estrategia de Gestión del Recurso Humano en Colombia ${ }^{57}$ basada en la creación de un Sistema Nacional de Calificaciones que, entre otros elementos, debía construirse sobre la base de un Marco Nacional de Calificaciones (MNC) y de un Sistema de Certificación de Competencias Laborales (sicecol). Estos instrumentos servirán para que el sistema de formación pueda adecuarse de manera más dinámica y efectiva a las necesidades del aparato productivo.

\section{IMPLEMENTAR SISTEMAS DE FORMACIÓN DUAL, INICIANDO POR LOS PROGRAMAS RELEVANTES A LAS INICIATIVAS CLUSTER Y/O APUESTAS PRODUCTIVAS}

La formación dual ha sido una de las principales estrategias adoptadas por países exitosos como Alemania para lograr una mayor pertinencia en la formación y aumentar los índices de empleabilidad de los jóvenes. El país necesita tomar una decisión más contundente para moverse hacia la construcción de un sistema dual potente.

\section{COFINANCIACIÓN DE PROGRAMAS NUEVOS RELACIONADOS A LAS APUESTAS DEL PAÍS BAJO LA PDP}

Es muy posible que el sistema de formación colombiano (a nivel universitario y de formación Ty $\mathrm{T}$ y FTDH) no ofrezca muchos de los programas que estarían necesitando las apuestas productivas del país. En la medida en que esta situación es susceptible de sufrir fallas de coordinación — no se abre un programa ya que no existe la suficiente demanda para hacerlo viable financieramente-, el Gobierno podría cofinanciar programas relevantes para las apuestas del país bajo la PDP. del sistema de formación de capital humano sfch" (Documento Conpes 3674, Bogotá, Consejo Nacional de Política Económica y Social, versión aprobada, ig de julio de 2010). 


\section{Institucionalidad para el Capital Humano en el marco de la PDP}

Si bien existe una Comisión Intersectorial de Gestión del Recurso Humano (cIGERH) encargada de la implementación del Conpes 3674 de 2010 , el tema de capital humano trasciende el Sistema Nacional de Calificaciones y amerita la creación de un Comité Temático de Capital Humano. Más allá de la implementación de este Conpes, la tarea más importante de este Comité sería articular los esfuerzos desde los ministerios y agencias públicas relevantes para dar respuestas a las necesidades de formación de las apuestas del país en el marco de la PDP, incluyendo aquellas de los departamentos.

\section{Conclusiones}

A lo largo de este documento se han recogido algunos de los planteamientos que en el mundo, en América Latina y el Caribe y en Colombia, se debaten en relación con la imperiosa necesidad de mejorar profundamente la educación y la formación para el trabajo, con miras a mejorar las condiciones de vida y de trabajo de las personas, especialmente de los jóvenes, lo cual redunda en el desarrollo social y económico de toda la población de los países.

La preocupación de contar con recursos humanos mejor educados y con los conocimientos, habilidades y competencias no es nueva; sin embargo, frente a las dificultades de inserción laboral de los jóvenes, quienes encuentran serias dificultades para conseguir un empleo estable y productivo o bien para emprender actividades de las mismas características, se ha redoblado. A pesar de las declaraciones políticas y buenas intenciones de todos los interlocutores sociales, los resultados son muy limitados.

Frecuentemente se hace referencia a la formación dual, en alternancia o la formación en el puesto de trabajo, la cual ha demostrado amplios beneficios en países como Alemania y Suiza, donde dicha capacitación ha sido el resultado de procesos históricos y culturales que configuran normas jurídicas y convicciones consuetudinarias, de principios didácticos y estructuras institucionales.

En Colombia, especialmente, surgen varias preguntas que deberían responderse con franqueza y actuar en consecuencia, aun cuando es claro que la "transferencia" del modelo alemán de formación dual no es posible ${ }^{8}$, pero si algunos de sus elementos. Entre los interrogantes, algunos son evidentes:

- ¿ ¿Goza la formación profesional, a los ojos del Estado y la economía, así como de la población, de una elevada consideración? ¿Quién destaca y cuya familia puede costearla, aspira a una titulación universitaria? 
- ¿ ¿Tiene la formación profesional una finalidad amplia? ¿Es un medio para alcanzar objetivos económicos, sociales e individuales?

- ¿Están las empresas comprometidas con la formación profesional? ¿Participan decididamente en la definición de las competencias requeridas? ¿Facilitan las empresas lugares de aprendizaje, por ejemplo, haciéndose responsables de la designación de tutores al interior de las empresas? ¿En las empresas, los cargos directivos son primordialmente ocupados por personas con formación académica o tienen acceso a esas posiciones quienes han hecho una formación técnica?

- ¿Permite la formación profesional la movilidad laboral, dentro de las empresas o los sectores productivos?

- ¿ ¿La formación profesional es una tarea colegiada entre el Estado y el sector productivo?

- ¿Cómo está calificado el personal docente y formativo? ¿Qué tipo de incentivos existen para los docentes? ¿Se realizan evaluaciones del personal docente y con qué frecuencia?

La educación y la formación, aún con mejoras sustanciales, no pueden, por si solas, resolver los problemas del empleo y de productividad; deberían ser coherentes y formar parte integrante de políticas y programas globales en el campo económico, social y del mercado de trabajo que promuevan el crecimiento económico, social y la ocupación.

En la mayoría de los países, incluyendo a Colombia, se han realizado numerosas investigaciones, diagnósticos y análisis que, de una u otra manera, plantean recomendaciones muy similares a pesar de lo cual son relativamente pocas las que se han puesto en práctica. $\mathrm{Al}$ mismo tiempo pareciera que hay temas "de moda", como es el de los marcos de calificaciones o cualificaciones (MC), pero vale la pena preguntarse si tales marcos resuelven un problema; en efecto "... uno de los grandes errores a evitar es depositar en la creación del MC expectativas poco ambiciosas o poco realistas..." 59 .

Las personas que han recibido una educación y formación escasas suelen ser los perdedores en el proceso de cambio económico, incluso en fases de crecimiento económico y de menores tasas de desempleo. La formación para el trabajo requiere de la diversificación de los prestatarios de servicios y la promoción de una sana competencia.

Finalmente, es importante fortalecer el circulo virtuoso entre los incrementos de la productividad laboral y la calidad del empleo, para los cual son elementos clave las mejoras en la educación, la formación profesional y la capacita- 
ción, así como el fortalecimiento de las organizaciones empresariales y sindicales y la promoción del diálogo social en todas sus formas.

\section{Bibliografía}

"8. ${ }^{a}$ edición del Seminario Especializado en Flexografía de la Región Centroamericana 'Flexo 20I 5'”. Consultado en septiembre de 20 I6. https://goo.gl/XnkTJR

Aranciba Muñoz, Eduardo y Palma Díaz, María Antonieta, eds. "Mejorando la productividad y la calidad: packing de uva”. Guía de Autoformación y Evaluación por Competencias (GAEC), Ministerio de Agricultura, Gobierno de Chile, diciembre de 2009.

Barrera Osorio, Felipe, Maldonado, Darío y Rodríguez, Catherine. "Calidad de la educación básica media en Colombia: diagnóstico y propuestas". Documento, Serie de documentos ceDE, núm. 4I, noviembre de 20I2. I4. https://goo.gl/uY47MJ

Bassi, Marina, Busso Matías, Urzúa Sergio y Vargas, Jaime. Desconectados: Habilidades, educación y empleo en América Latina. Washington: BID, $20 \mathrm{I} 2$.

Billorou, Nina y Vargas, Fernando. "Herramientas básicas para el diseño e implementación de Marcos de Cualificaciones". Guía de trabajo, огт/Cinterfor, 2o ıo. https://goo.gl/VUGgro

Comisión Económica para América Latina y el Caribe (CEPAL) y Organización Internacional del Trabajo (огт). “Coyuntura laboral en América Latina y el Caribe”. Documento, oiт, mayo de 2012 .

Comisión Europea. "Work-Based Learning in Europe, Practices and Policy Pointers". Documento oficial, junio 2013 . https://goo.gl/hnoEGp.

Consejo Privado de Competitividad. "Informe Nacional de Competitividad 20 I4-20 I 5". Informe, Bogotá, I 8 de octubre de 20I4. https://goo.gl/zBLjN7.

Cruz Caruso, Luiz Antonio y Bastos Tigre, Paulo, coord. "Modelo senai de prospecção”. Documento metodológico, Papeles de la Oficina Técnica, Cinterfor y oІт, 2004.

Departamento Nacional de Planeación (DNP). "Lineamientos de política para el fortalecimiento del sistema de formación de capital humano sfch". Documento Conpes 3674, Bogotá, Consejo Nacional de Política Económica y Social, versión aprobada, i9 de julio de 20 Io.

Euler, Dieter. “El sistema dual en Alemania: ¿Es posible transferir el modelo al extranjero?” Estudio, Fundación Bertelsmann, 2013.

Becker, Carsten. "Accompanying Research for the Special Programme of the Federal Government for the Introductory Qualification of Adolescents. EQJ Programme". Reporte final, The Federal Ministry for Labour and Social Affairs, Berlín, 2008. https:/goo.gl/CJntd2

FIESP, CiEsp. "Meu novo mundo. O projeto". Consultado en septiembre de 20r6. https://goo.gl/ $\mathrm{mUkvgX.}$

Harvard, Graduate School of Education. "Pathways to Prosperity". Documento oficial, febrero de 20I I. https://goo.gl/iRoNHw.

Llisterri, Juan José; Gligo, Nicolo; Homs, Oriol y Ruiz Devesa, Domenec. "Educación técnica y formación profesional en América Latina: el reto de la productividad”. Documento oficial, Serie Políticas Públicas y Transformación Productiva, núm. I3, caf. 25. https://goo. gl/6QQavw. 
Ministério do Trabalho e Emprego. Manual da Aprendizagem: O que é preciso saber para contratar o aprendiz. $8^{\text {a }}$ ed. Revisada y ampliada. Brasilia: Assessoria de Comunicação do mte, 2013. https://goo.gl/owcgto.

ocded, CePal. Perspectivas económicas de América Latina 2013: políticas de pymes para el cambio estructural. oCDED, CEPAL, 20I2. I47. doi http://dx.doi.org/ro. I787/leo-20I3-es.

Organización Internacional del Trabajo (oIT). "Calificaciones para la mejora de la productividad, el crecimiento del empleo y el desarrollo". Informe v, quinto punto del orden del día, Conferencia Internacional del Trabajo, 97. reunión, огт, 2008.

Organización Internacional del Trabajo (огт). Conclusiones sobre las calificaciones para la mejora de la productividad, el crecimiento del empleo y el desarrollo. Conferencia Internacional del Trabajo 2008 , I. ${ }^{a}$ ed. Ginebra, Suiza: Oficina Internacional del Trabajo, 2008.

Organización Internacional del Trabajo (огт). “Trabajo Decente en las Américas: Una agenda hemisférica, 2006-2015”. (Informe del director general sobre la XVI Reunión Regional Americana, Brasilia, mayo de 2006), I, https://goo.gl/2yJYuV.

Organización Internacional del Trabajo (orт)/Cinterfor. Cinterfor: 5 o años. Montevideo: orт/Cinterfor, 20I3. https://goo.gl/bLexAD.

Pronk, Marcela. Recomendación I95 de OIT. Cuestiones históricas y actuales. оIт, 2005. https://goo. $\mathrm{gl} / 2 \mathrm{LoLFp}$.

Radio Latin-Amerika (blog). https://goo.gl/6rqzcd.

Red de Instituciones de Formación Profesional. "Anticipación de las competencias profesionales. Transferencia del Modelo sEnaI de Prospectiva". Documento de trabajo, Montevideo, oIT y Cinterfor, 2013. https://goo.gl/O2JuHC.

senac. "Aprendizagem Profissional Comercial". Consultado en septiembre de 20I6. https://goo. $\mathrm{gl} / \mathrm{x} \mathrm{Tv} \mathrm{ZgH}$.

SENAC. "Programa de Aprendizagem Profissional Comercial. Referenciais para a ação SENAC". Serie de documentos técnicos, sENAC, Rio de Janeiro, diciembre de 2006. https://goo.gl/3pXzQb.

SENAI. "Aprendizagem Industrial. Manual de Orientações às empresas". Departamento Regional

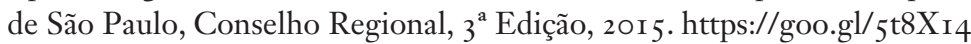

Weller, Jürgen. "Aspectos de la evolución reciente de los mercados laborales de América Latina y el Caribe", Revista CEPAL, núm. I I4 (diciembre de 2014): 7-29.

Tueros, Marco; Dini, Marco; Polo, Patricia; Poma, Lucio y Henríquez, Lyzette. "Crisis internacional y políticas para las mipymes: desafíos y oportunidades para América Latina y Europa". Documento realizado en ocasión del seminario "Crisis Internacional y Políticas para las mipymes", Santiago de Chile, I 3 y I4 de octubre de 2009. https://goo.gl/svJzOw. 